\title{
Higher Order Moments of the Order Statistics for the Rectangular, Exponential, Gamma and Weibull Distributions
}

\author{
Sampath Kumar and V. V. Hara Gopal
}

\begin{abstract}
In this paper we discuss the problem of Higher Order Moments for the order Statistics for the Rectangular, Exponential, Gamma and Weibull distributions by finding the order statistic distributions for the base distribution and modified distributions, the base distribution is to deduce the corresponding distribution by the polynomial modifier. These higher order moments are very much useful in most of the Data sciences and Image analysis.
\end{abstract}

Key words - Higher order Moments, Base and Modifier Distributions.

\section{INTRODUCTION}

In this paper we consider the procedure of finding out the higher order moments [4]-[6] for order statistic distribution for Rectangular, Exponential, Gamma and Weibull distributions. For these distributions we first find out the order statistic distribution and treat this as the base distribution and modify the corresponding distribution by considering the polynomial modifier [7], [13] that is,

$$
f_{m}(x)=\left(n \cdot f(x)(F(x))^{n-1}\right)\left\{1+\alpha \mathrm{g}\left(\mathrm{x}_{\mathrm{n}}\right)\right\}
$$

This gives us the modifier expression of the maximum order statistic distribution. Similarly, we consider the modifier of the minimum order statistic distribution as:

$$
f_{m}(x)=\left(n \cdot f(x)(1-F(x))^{n-1}\right){ }_{\{1+} \alpha \mathrm{g}(\mathrm{xn})
$$

With the above two modifier functions we compute the higher order moments for base and as well as for the modifier distributions.

For these Minimum and Maximum order statistic distributions, higher order moments [8] are computed by considering different sample sizes, that is $n=2,3,5$ and 10 these are computed by assuming that the first four moments of these order statistic distributions are made equal and the higher order moments computed, which are different from base. As the sample size increases the moment differences are increasing to some extent, this is true for all the sample sizes considered. This aspect is discussed in detail in the following sections

\section{Distributions Whose First K Moments Are IDENTICAL}

Let $f_{i}(x)$ and $f_{m}(x)$ be two probability density functions of random variates whose first $\mathrm{k}$ moments are the same, but whose higher order moments differ. Then, we can write

Published on July 21, 2021.

Sampath Kumar

(e-mail: sampath.k@hotmail.com) $f_{\mathrm{m}}(x)=f_{\mathrm{i}}(x)\left\{1+\alpha g\left(x_{\mathrm{n}}\right)\right\}$, where $g(x n)$ is a "modifier" function such that $f_{i}(x) g\left(x_{n}\right)$ is bounded over the domain of definition of $x$,

Integrates to zero and, $\alpha$ is a suitably chosen modifier weight.

Since the first $\mathrm{k}$ moments should be the same for both the distributions, one should have:

$$
\int_{x} f_{m}(x) x^{r} d x=\int_{x} f_{i}(x) x^{r} d x \text { for } \mathrm{r}=1,2,3, \ldots, \mathrm{k}
$$

i.e., one should have:

$$
\int_{x} f_{i}(x) g\left(x_{n}\right) x^{r} d x=0 \text { for } \mathrm{r}=1,2,3, \ldots, \mathrm{k}
$$

This fact enables one to generate a class of functions $f_{m}(x)$, with $f_{i}(x)$ (included in this class) as its base function; all these functions are to have their first $\mathrm{k}$ moments the same as the corresponding moments of the base distribution.

It is not difficult to envisage such a function $g\left(x_{n}\right)$. An obvious choice is supplied by orthogonal system of functions, with $f_{i}(x)$ as the kernel. In particular, $g\left(x_{n}\right)$ may be a polynomial $\mathrm{P}_{\mathrm{m}}(\mathrm{x})$ of degree more than $\mathrm{k}$ if $\mathrm{x}$ has a finite range and $\mathrm{P}_{\mathrm{m}}(\mathrm{x}) \cdot \mathrm{w}(\mathrm{x})$, where $\mathrm{w}(\mathrm{x})$ is a suitable dampening function like $e^{-x}$ or $e^{-x^{2}}$ if the range of $\mathrm{x}$ is not finite. That is if $\mathrm{x}$ has a finite range, we will take $\mathrm{w}(\mathrm{x})=1$ and if $\mathrm{x}$ has a infinite range we will take $\mathrm{w}(\mathrm{x})=e^{-x}$ or $e^{-x^{2}}$ We take here that ' $x$ ' has a finite range for Rectangular variate and an infinite range $(0 \leq$ $x \leq \infty)$ for Exponential variate, so here we take for this variate, $\mathrm{g}\left(x_{\mathrm{n}}\right)=\mathrm{P}_{\mathrm{m}}(\mathrm{x}) \cdot \mathrm{w}(x)$.

Let $\mathrm{P}_{\mathrm{m}}(\mathrm{x})$ be a polynomial defined as $\mathrm{b}_{0}+\mathrm{b}_{1} \mathrm{x}+\mathrm{b}_{2} \mathrm{x}^{2}+\mathrm{b}_{3} \mathrm{x}^{3}+$ $\ldots+b_{m} x^{m}$ such that:

$$
\int_{x} f_{i}(x) P_{m}(x) w(x) x^{r}=0 \text { for } \mathrm{r}=0,1,2, \ldots \mathrm{k}
$$

It is obviously possible to obtain such polynomial $\mathrm{P}_{\mathrm{m}}(x)$ for $f_{i}(x)$, if the first $\mathrm{k}$ moments exist. Also, under the same assumptions, it is obvious that $g\left(x_{n}\right) f_{i}(x)$ is finite for all valid values of $x$.

Let $\theta=\max _{x}\left|\mathrm{P}_{\mathrm{m}}(x) \mathrm{w}(x)\right|$ be the maximum absolute value that $\mathrm{P}_{\mathrm{m}}(x) \mathrm{w}(x)$ takes over the range of interest.

Then $f_{m}(x)=f_{i}(x)\left\{1+\alpha\left(g\left(x_{n}\right)=\operatorname{Pm}(x) \mathrm{w}(x)\right)\right\}$ will be non negative for all $x$ values if $|\alpha|<\frac{1}{\theta}$ and we will have $f_{m}(x)$ as a class of density functions which have the first ' $\mathrm{k}$ ' moments as $\mathrm{f}_{\mathrm{i}}(\mathrm{x})$ does.

V. V. Hara Gopal

(e-mail: haragopal_vajjha@yahoo.com) 
The difference between the $\mathrm{r}^{\text {th }}$ moment of $f_{m}(x)$ and $f_{i}(x)$, is defined as $\Delta_{\mathrm{r}}$

$$
\begin{aligned}
& \Delta_{\mathrm{r}}=\int_{x}\left\{\left(f_{m}(x)-f_{i}(x)\right)\right\} x^{r} d x \\
& =\alpha\left\{\int_{x} f_{i}(x) P_{m}(x) w(x) x^{r} d x\right\} \\
& =\alpha\left\{\sum_{s=0}^{m} b_{s} \int_{x} f_{i}(x) w(x) x^{r+s} d x\right\}
\end{aligned}
$$

i.e. $\Delta_{\mathrm{r}}=\alpha\left\{\sum_{s=0}^{m} b_{s} \mu_{s+r}^{\prime}\right\}$ where $\mu_{s+r}^{\prime}$ is the moment of $\operatorname{order}(\mathrm{r}+\mathrm{s})$, of the density function $f_{i}(x) \mathrm{w}(x)$.

In other words, one has:

$\alpha\left(\mathrm{b}_{0} \mu_{r}^{\prime}+\mathrm{b}_{1} \mu_{r+1}^{\prime}+\mathrm{b}_{2} \mu_{r+2}^{\prime}+\mathrm{b}_{3} \mu_{r+3}^{\prime}+\ldots+\mathrm{b}_{\mathrm{m}} \mu_{r+m}^{\prime}\right)=\Delta_{\mathrm{r}}, \mathrm{r}$ $=0,1, \ldots \ldots .$.

Using matrix notation, one can restate this result as follows:

$\mathbf{M}=\left[\begin{array}{cccccc}\mu_{0}^{\prime} & \mu_{1}^{\prime} & \cdot & . & \cdot & \mu_{m}^{\prime} \\ \mu_{1}^{\prime} & \mu_{2}^{\prime} & \cdot & \cdot & \cdot & \mu_{m+1}^{\prime} \\ \cdot & \cdot & \cdot & \cdot & \cdot & \cdot \\ \cdot & \cdot & \cdot & \cdot & \cdot & \cdot \\ \cdot & \cdot & \cdot & \cdot & \cdot & \cdot \\ \mu_{k}^{\prime} & \mu_{k+1}^{\prime} & \cdot & \cdot & \cdot & \mu_{m+k}^{\prime} \\ \mu_{k+1}^{\prime} & \mu_{k+2}^{\prime} & \cdot & \cdot & \cdot & \mu_{m+k+1}^{\prime} \\ \cdot & \cdot & \cdot & \cdot & \cdot & \cdot \\ \cdot & \cdot & \cdot & \cdot & \cdot & \cdot \\ \cdot & \cdot & \cdot & \cdot & \cdot & .\end{array}\right], \bar{b}=\left[\begin{array}{c}b_{0} \\ b_{1} \\ \cdot \\ \cdot \\ \cdot \\ b_{m}\end{array}\right]$

$$
\text { and } \bar{\Delta}=\left[\begin{array}{c}
\Delta_{0} \\
\Delta_{1} \\
\cdot \\
\cdot \\
\cdot \\
\Delta_{k} \\
\Delta_{k+1} \\
\cdot \\
\cdot \\
\cdot
\end{array}\right]
$$

Since the moment differences $\Delta_{0}, \Delta_{1}, \ldots, \Delta_{k}$ are to be equal to zero. One should have

$$
\alpha \cdot \text { M. } \bar{b}=\bar{o}
$$

where $\mathrm{M}$ is of order $(\mathrm{k}+1, \mathrm{~m}+1)$, the coefficient vector $\bar{b}$ of order $\mathrm{m}+1$ and $\bar{o}$ is of order $\mathrm{k}+1$.

Since the equation system is homogeneous, one can take $b_{m}=1$. The rank of the matrix $M$ is $1+\min (k, m)$. Hence, if $\mathrm{k}=\mathrm{m}$, the only solution is the trivial solution $\bar{b}=\bar{o}$. Hence, $\mathrm{m}$, the degree of the polynomial, is to be greater than $\mathrm{k}$.

Taking $\mathrm{k}=4$, that is the first four moments should be the same, one should have $m \geq 5$.

The solution set $\bar{b}$ is a vector space of dimension (m-k), and any linear combination of these solutions will give an acceptable polynomial $\mathrm{P}_{\mathrm{m}}(x)$. As already noted, (since the polynomial is bounded in the range of interest) proper choice of the modifier -scalar $\alpha$ values makes $1+\alpha \mathrm{P}_{\mathrm{m}}(x) \mathrm{w}(x)$ nonnegative in the region of interest, i.e. $f_{\mathrm{m}}(x) \stackrel{\Delta}{=} f_{\mathrm{i}}(x)\left\{1+\alpha \mathrm{P}_{\mathrm{m}}(x)\right.$ $\mathrm{w}(x)\}$ will be density function, all having the first $\mathrm{k}$ moments same with $f_{\mathrm{i}}(x)$. The other higher, moments can easily be obtained as functions of the ' $b$ '-coefficients as chosen above.

We shall now construct a family of distributions having the first four moments same as those of the base distribution $f_{\mathrm{n}}(x)$, where $i=1,2,3 \ldots, n$ defined by:

$$
\begin{gathered}
f_{1}(x)=\frac{d(F(x))}{d x}, f_{2}(x)=\frac{d\left((F(x))^{2}\right)}{d x},--\cdot, \\
f_{n}(x)=\frac{d\left((F(x))^{n}\right)}{d x} \\
f_{n}(x)=\frac{d\left((F(x))^{n}\right)}{d x}=\frac{d}{d x}\left(F_{n}(x)\right)=n \cdot f(x)(F(x))^{n-1}
\end{gathered}
$$

where $F_{2}(x)=(F(x))^{2}$ that is the square of the distribution of ' $x$ ' , where the squaring process is monotonic and $f_{2}(x)=\frac{d}{d x}\left(F_{2}(x)\right)=2 . f(x)(F(x))$ is the density of ' $x$ ' the "second iterate" that is the $2^{\text {nd }}$ order statistic distribution is considered and the standardized moments are computed. In the next section we consider various distributions of order statistic and their moments.

\section{RECTANGULAR Distribution}

We shall now consider the Rectangular Distribution, defined by:

$$
F(x)=x, 0 \leq x \leq 1,
$$

and now the Minimum Order statistic density function of Rectangular Distribution is:

$$
f_{n}(x)=n \cdot(1-x)^{n-1}
$$

and Maximum Order statistic density function of Rectangular Distribution is:

$$
f_{n}(x)=n \cdot x^{n-1}
$$

where ' $\mathrm{n}$ ' is the sample size.

Now we consider the polynomials of order 5 as the modifier i.e. $\mathrm{k}=4, \mathrm{~m}=5$ (polynomial order), one gets $\mathrm{M}$, such that:

$$
\alpha . \text { M. } \bar{b}=\bar{\Delta}
$$

Solving the above equation for ' $\bar{b}$, we get the modifier polynomial coefficients as ' $\bar{b}$, from which we get the 
following $5^{\text {th }}$ degree polynomial in ' $x$ ' with ' $n$ ', the sample size.

\section{A. Minimum Order Statistic for Rectangular Distribution}

The following Table I gives the polynomials and the corresponding ' $\theta$ ' values for a chosen value of the ' $n$ '.

TABLE I: POLYNOMIALS AND THE CORRESPONDING ‘ $\theta$ ' VALUES FOR A CHOSEN VALUe OF THE ' $\mathrm{N}$ '

\begin{tabular}{|c|c|c|}
\hline $\mathrm{n}$ & $g\left(x_{\mathrm{n}}\right)$ & $\theta=\max _{x}\left|g\left(x_{\mathrm{n}}\right)\right|$ \\
\hline 2 & $\begin{array}{c}-0.002165+0.07575876 * x- \\
0.606061 * x^{2}+1.818182 * x^{3}- \\
2.272727 * x^{4}+x^{5}\end{array}$ & 0.012987 \\
\hline 3 & $\begin{array}{c}-0.001263+0.050505 * x- \\
0.454546 * x^{2}+1.515152 * x^{3}- \\
2.083333 * x^{4}+x^{5}\end{array}$ & 0.026515 \\
\hline 5 & $\begin{array}{c}-0.0004995+0.024975 * x- \\
0.274725 * x^{2}+1.098901 * x^{3}- \\
1.785714 * x^{4}+x^{5}\end{array}$ & 0.062937 \\
\hline 10 & $\begin{array}{c}-0.000086+0.0064499 * x- \\
0.103199 * x^{2}+0.584795 * x^{3}- \\
1.315789 * x^{4}+x^{5}\end{array}$ & 0.172171 \\
\hline
\end{tabular}

Table II below gives the ' $\alpha$ ' for the different ' $n$ ' and ' $\theta$ ' values.

TABLE II: $\alpha$ VALUES FOR THE DIFFERENT 'N' AND ' $\theta$ ' VALUES

\begin{tabular}{ccccc}
\hline $\mathrm{n}$ & 2 & 3 & 5 & 10 \\
\hline$\theta$ & 0.012987 & 0.026515 & 0.062937 & 0.172171 \\
$\alpha=\frac{1}{\theta}$ & 77.00 & 37.714 & 15.888889 & 5.808192 \\
\hline
\end{tabular}

Thus, the general formula for modified minimum order statistic distributions is:

$f_{m}(x)=\left(n . f(x)(1-F(x))^{n-1}\right)\left\{1+\alpha g\left(x_{\mathrm{n}}\right)\right\}$

Thus, for instance, when $\mathrm{n}=2$, we have:

$$
f_{\mathrm{m}}(x)=2 .(1-x) .\left\{1+\alpha g\left(x_{\mathrm{n}}\right)\right\} \text {, and } \alpha \leq 77.00
$$

When $\mathrm{n}=3$, we have $f_{\mathrm{m}}(x)=3 .(1-x)^{2} \cdot\left\{1+\alpha g\left(x_{\mathrm{n}}\right)\right\}$, and $\alpha \leq 37.714$. When $\mathrm{n}=5$, we have $f_{\mathrm{m}}(x)=5^{*}(1-x)^{4} \cdot\{1+\alpha$ $\left.g\left(x_{\mathrm{n}}\right)\right\}$, and $\alpha \leq 15.889$ and when $\mathrm{n}=10$, we have $f_{\mathrm{m}}(x)=$ $10 *(1-x)^{9} \cdot\left\{1+\alpha g\left(x_{\mathrm{n}}\right)\right\}$, and $\alpha \leq 5.809$.

Similarly, $f_{\mathrm{m}}(x)$ can be computed for any value of ' $\mathrm{n}$ '.

Table III (a), Table III (b), Table III (c) and Table III (d) clearly show that the first four standardized moments (first two moments are actual moments, i.e., mean and variance) are same for base and modified distributions and higher order moments are different.

Standardized Moments for base, modified distribution and their difference.
TABLE III (A): FOR THE CASE OF N=2 AND $\alpha=77.00$

\begin{tabular}{cccc}
\hline Moment & Base & Modified & Difference \\
\hline 2 & 0.0556 & 0.0556 & 0 \\
3 & 0.565685 & 0.565685 & 0 \\
4 & 2.4 & 2.4 & 0 \\
5 & 3.232488 & 3.315138 & 0.082650 \\
6 & 8.857143 & 9.126876 & 0.269733 \\
7 & 16.970563 & 18.03865 & 1.068087 \\
8 & 41.6 & 44.8224 & 3.2224 \\
9 & 92.155298 & 102.08848 & 9.933182 \\
10 & 222.54546 & 251.06721 & 28.52175 \\
11 & 525.6523 & 607.20358 & 81.55128 \\
12 & 1283.517 & 1511.2094 & 227.6924 \\
13 & 3134.22 & 3766.2267 & 632.0067 \\
14 & 7772.8 & 9510.5278 & 1737.7278 \\
15 & 19377.1 & 24135.983 & 4758.883 \\
\hline
\end{tabular}

TABLE III (B): FOR THE CASE OF N=3 AND $\alpha=37.714$

\begin{tabular}{cccc}
\hline Moment & Base & Modified & Difference \\
\hline 1 & 0.25 & 0.25 & 0 \\
2 & 0.0375 & 0.0375 & 0 \\
3 & 0.860662 & 0.860662 & 0 \\
4 & 3.095238 & 3.095238 & 0 \\
5 & 6.147593 & 6.198542 & 0.050949 \\
6 & 17.416226 & 17.698124 & 0.281898 \\
7 & 45.42388 & 46.799542 & 1.375662 \\
8 & 130.05051 & 135.83888 & 5.78837 \\
9 & 375.2722 & 398.37987 & 23.10767 \\
10 & 1120.9855 & 1209.5911 & 88.6056 \\
11 & 3407.667 & 3739.9026 & 332.2356 \\
12 & 10562.556 & 11789.079 & 1226.523 \\
13 & 33233.05 & 37716.241 & 4483.191 \\
14 & 106003.64 & 122280.85 & 16277.21 \\
15 & 342117.6 & 400957.33 & 58839.73 \\
\hline
\end{tabular}

TABLE III (C): FOR THE CASE OF N=5 AND $\alpha=15.889$

\begin{tabular}{cccc}
\hline Moment & Base & Modified & Difference \\
\hline 1 & 0.16667 & 0.16667 & 0 \\
2 & 0.01984 & 0.01984 & 0 \\
3 & 1.183216 & 1.183216 & 0 \\
4 & 4.2 & 4.2 & 0 \\
5 & 11.264216 & 11.288047 & 0.023831 \\
6 & 37.59636 & 37.807835 & 0.211475 \\
7 & 128.39399 & 129.83641 & 1.44242 \\
8 & 468.91698 & 477.53168 & 8.6147 \\
9 & 1781.7589 & 1829.9506 & 48.1917 \\
10 & 7029.1448 & 7288.6934 & 259.5486 \\
11 & 28587.686 & 29954.61 & 1366.924 \\
12 & 119386.001 & 126488.55 & 7102.549 \\
13 & 510100.99 & 546713.37 & 36612.38 \\
14 & 2223643.53 & 2411541 & 187897.47 \\
15 & 9866436.27 & 10828723 & 962286.73 \\
\hline
\end{tabular}

TABLE III (D): FOR THE CASE OF N=10 AND $\alpha=5.809$

\begin{tabular}{cccc}
\hline Moment & Base & Modified & Difference \\
\hline 1 & 0.09091 & 0.09091 & 0 \\
2 & 0.00689 & 0.00689 & 0 \\
3 & 1.516770 & 1.516770 & 0 \\
4 & 5.775824 & 5.775824 & 0 \\
5 & 20.038701 & 20.044157 & 0.005456 \\
6 & 83.397363 & 83.474215 & 0.076852 \\
7 & 375.06336 & 375.8491 & 0.78574 \\
8 & 1827.20232 & 1834.2379 & 7.03558 \\
9 & 9480.0669 & 9539.1617 & 59.0948 \\
10 & 51925.7092 & 52405.98 & 480.2708 \\
11 & 297950.801 & 301789.61 & 3838.809 \\
12 & 1780303.63 & 1810761.5 & 30457.87 \\
13 & 11023008.96 & 11264217 & 241208.04 \\
14 & 70438092.6 & 72351227 & 1913134.4 \\
15 & 462966384.8 & 478195650 & 15229265.2 \\
\hline
\end{tabular}


Base, Modified densities (of distributions) and their differences for different values of ' $\mathrm{n}$ ' and ' $\alpha$.

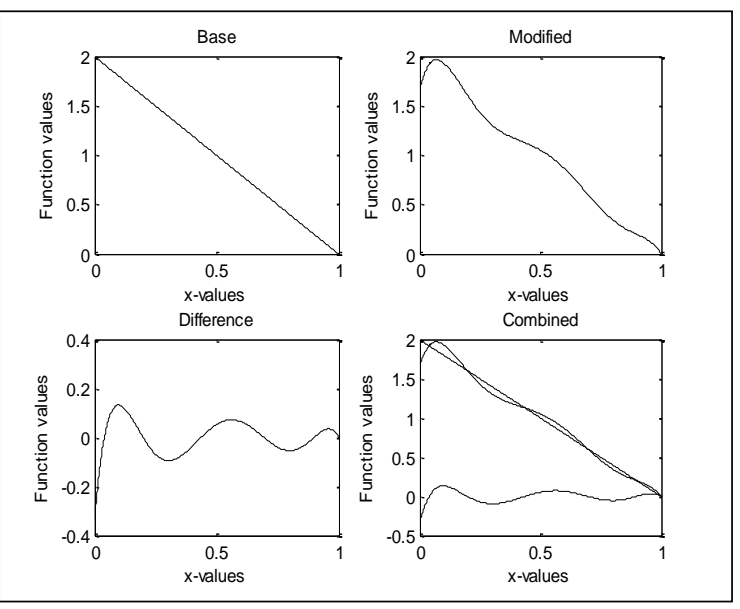

Fig. 1 (a). For the case of $\mathrm{n}=2$ and $\alpha=77.00$.

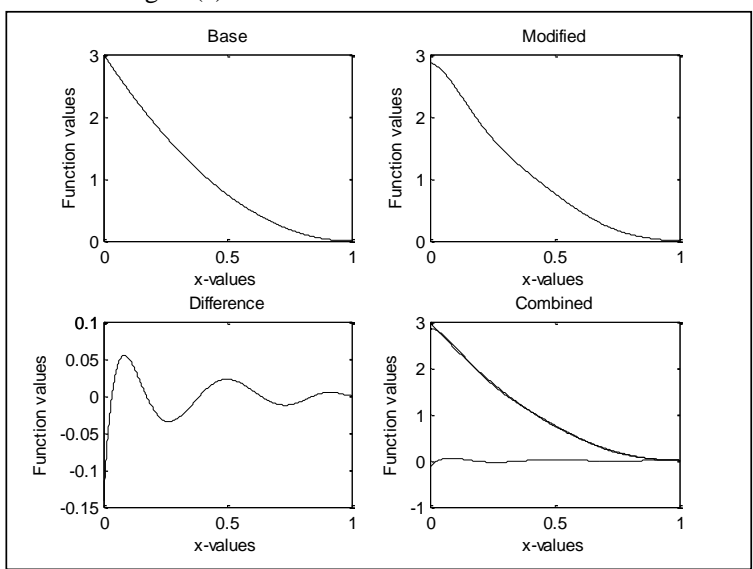

Fig. 1 (b). For the case of $n=3$ and $\alpha=37.714$.

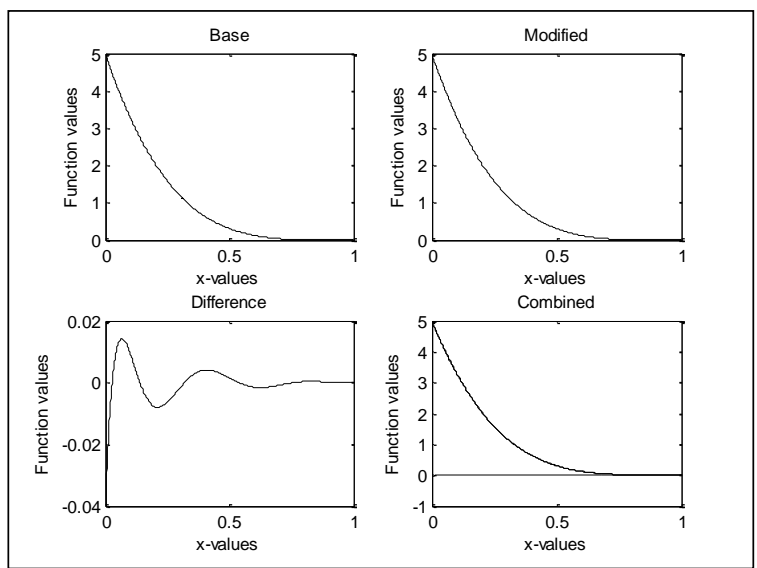

Fig. 1 (c). For the case of $\mathrm{n}=5$ and $\alpha=15.889$.

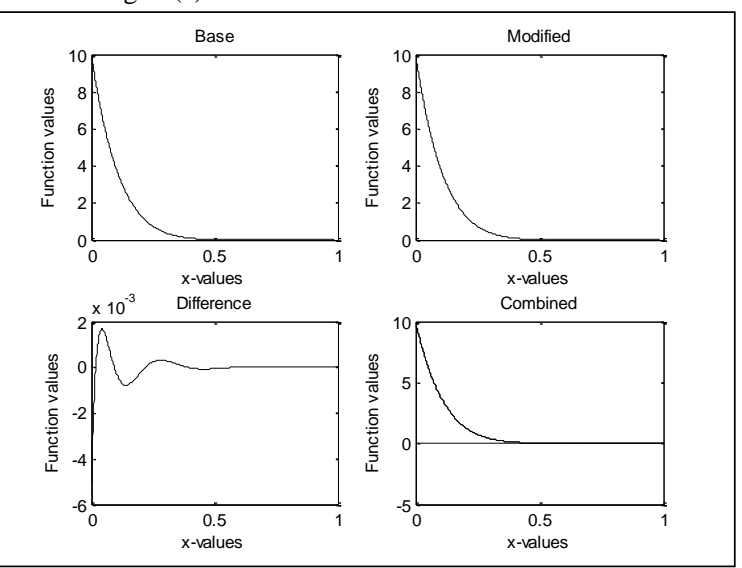

Fig. 1 (d). For the case of $\mathrm{n}=10$ and $\alpha=5.809$.

\section{B. Maximum Order Statistic for Rectangular Distribution}

The following Table IV gives the polynomials and the corresponding ' $\theta$ ' values for the chosen values of ' $n$ '.

TABLE IV: POLYNOMIALS AND THE CORRESPONDING ' $\theta$ ' VALUES FOR A CHOSEN VALUe OF THE ' $\mathrm{N}$ '

\begin{tabular}{ccc}
\hline & $g\left(x_{\mathrm{n}}\right)$ & $\theta=\max _{t}\left|g\left(x_{\mathrm{n}}\right)\right|$ \\
\cline { 2 - 3 } 2 & $-0.012987+0.227273^{*} x-$ & 0.012987 \\
3 & $1.212121^{*} x^{2}+2.727273^{*} x^{3}-2.727273 * x^{4}+x^{5}$ & \\
& $-0.026515+0.353535^{*} x-$ & \\
& $1.590909 * x^{2}+3.181818^{*} x^{3}-2.916667 * x^{4}+x^{5}$ & 0.026515 \\
5 & $-0.062937+0.629371 * x-$ & \\
& $2.307692 * x^{2}+3.956044 * x^{3}-3.214286^{*} x^{4}+x^{5}$ & 0.062937 \\
10 & $-0.172171+1.291279 * x-$ & \\
& $3.756449 * x^{2}+5.321637 * x^{3}-3.684211^{*} x^{4}+x^{5}$ & 0.172171 \\
\hline
\end{tabular}

Table $\mathrm{V}$ below gives the $\alpha$ for different $\mathrm{n}$ and $\theta$ values.

\begin{tabular}{ccccc} 
TABLE V: & $\alpha$ & VALUES FOR THE DIFFERENT 'N' AND ' $\theta$ ' VALUES \\
\hline $\mathrm{n}$ & 2 & 3 & 5 & 10 \\
\hline$\theta$ & 0.0129 & 0.026515 & 0.062937 & 0.172171 \\
$\alpha=$ & 87 & & & \\
$\frac{1}{\theta}$ & 77.00 & 37.714 & 15.888889 & 5.808192 \\
\hline
\end{tabular}

Thus, the general formula for modified maximum order statistic distribution is:

$$
f_{m}(x)=\left(n \cdot f(x)(F(x))^{n-1}\right)\left\{1+\alpha g\left(x_{\mathrm{n}}\right)\right\}
$$

Thus, for instance, when $n=2$, we have:

$$
f_{\mathrm{m}}(x)=2 . x .\left\{1+\alpha g\left(x_{\mathrm{n}}\right)\right\} \text {, and } \alpha \leq 77.00
$$

When $\mathrm{n}=3$, we have $f_{\mathrm{m}}(x)=3 * x^{2} \cdot\left\{1+\alpha g\left(x_{\mathrm{n}}\right)\right\}$, and $\alpha \leq$ 37.714. When $\mathrm{n}=5$, we have $f_{\mathrm{m}}(x)=5^{*} x^{4} .\left\{1+\alpha g\left(x_{\mathrm{n}}\right)\right\}$, and $\alpha \leq 15.889$ and when $\mathrm{n}=10$, we have $f_{\mathrm{m}}(x)=10^{*} x^{9} \cdot\{1+\alpha$ $\left.g\left(x_{\mathrm{n}}\right)\right\}$, and $\alpha \leq$ 5.808. Similarly, $f_{\mathrm{m}}(x)$ can be computed for any value of ' $n$ '.

Table VI (a), Table VI (b), Table VI (c) and Table VI (d) clearly show that the first four standardized moments (first two moments are actual moments, i.e., mean and variance) are same for base and modified distributions and higher order moments are different.

Standardized Moments for base, modified distributionsand their difference.

\begin{tabular}{cccc}
\multicolumn{4}{c}{ TABLE VI (A): FOR THE CASE OF N=2 AND $\alpha=77.00$} \\
\hline Moment & Base & Modified & Difference \\
\hline 1 & 0.6667 & 0.6667 & 0 \\
2 & 0.0557 & 0.0557 & 0 \\
3 & -0.56569 & -0.56569 & 0 \\
4 & 2.4 & 2.4 & 0 \\
5 & -3.232488 & -3.149862 & 0.082626 \\
6 & 8.857143 & 8.587443 & -0.269700 \\
7 & -16.970563 & -15.902591 & 1.067972 \\
8 & 41.6 & 38.377831 & -3.222169 \\
9 & -92.155298 & -82.222764 & 9.932534 \\
10 & 222.54546 & 194.02521 & -28.52025 \\
11 & -525.6523 & -444.10499 & 81.54731 \\
12 & 1283.517 & 1055.8334 & -227.6836 \\
13 & -3134.221 & -2502.24 & 631.981 \\
14 & 7772.8 & 6035.14 & -1737.66 \\
15 & -19377.06 & -14618.299 & 4758.761 \\
\hline
\end{tabular}


TABLE VI (B): FOR THE CASE OF N=3 AND $\alpha=37.714$

\begin{tabular}{cccc}
\hline Moment & Base & Modified & Difference \\
\hline 1 & 0.75 & 0.75 & 0 \\
2 & 0.0375 & 0.0375 & 0 \\
3 & -0.860663 & -0.860663 & 0 \\
4 & 3.095235 & 3.095235 & 0 \\
5 & -6.147593 & -6.096628 & 0.050965 \\
6 & 17.416226 & 17.134291 & -0.281935 \\
7 & -45.423879 & -44.048096 & 1.375783 \\
8 & 130.05051 & 124.26178 & -5.78873 \\
9 & -375.2723 & -352.16344 & 23.10886 \\
10 & 1120.986 & 1032.3761 & -88.6099 \\
11 & -3407.667 & -3075.4184 & 332.2486 \\
12 & 10562.556 & 9335.9913 & -1226.564 \\
13 & -33233.051 & -28749.723 & 4483.328 \\
14 & 106003.64 & 89725.97 & -16277.67 \\
15 & -342117.6 & -283276.27 & 58841.33 \\
\hline
\end{tabular}

TABLE VI (C): FOR THE CASE OF N=5 AND $\alpha=15.889$

\begin{tabular}{cccc}
\hline Moment & Base & Modified & Difference \\
\hline 1 & 0.83333 & 0.83333 & 0 \\
2 & 0.01984 & 0.01984 & 0 \\
3 & -1.18323 & -1.18323 & 0 \\
4 & 4.2 & 4.2 & 0 \\
5 & -11.264216 & -11.240479 & 0.023737 \\
6 & 37.596364 & 37.385182 & -0.211182 \\
7 & -128.39399 & -126.95269 & 1.4413 \\
8 & 468.9169 & 460.30656 & -8.61034 \\
9 & -1781.7589 & -1733.5846 & 48.1743 \\
10 & 7029.145 & 6769.6681 & -259.4769 \\
11 & -28587.686 & -27221.069 & 1366.617 \\
12 & 119386.001 & 112284.8 & -7101.201 \\
13 & -510100.99 & -473494.57 & 36606.42 \\
14 & 2223643.53 & 2035773 & -187870.53 \\
15 & -9866436.27 & -8904273.2 & 962163.07
\end{tabular}

TABLE VI (D): FOR THE CASE OF N=10 AND $\alpha=5.808$

\begin{tabular}{cccc}
\hline Moment & Base & Modified & Difference \\
\hline 1 & 0.90909 & 0.90909 & 0 \\
2 & 0.00689 & 0.00689 & 0 \\
3 & -1.51676 & -1.51676 & 0 \\
4 & 5.77582 & 5.77582 & 0 \\
5 & -20.038701 & -20.033232 & 0.005469 \\
6 & 83.39736 & 83.320461 & -0.076899 \\
7 & -375.06336 & -374.27738 & 0.78598 \\
8 & 1827.2023 & 1820.1655 & -7.0368 \\
9 & -9480.0669 & -9420.9659 & 59.101 \\
10 & 51925.709 & 51445.403 & -480.306 \\
11 & -297950.801 & -294111.79 & 3839.011 \\
12 & 1780303.63 & 1749844.5 & -30459.13 \\
13 & -11023008.97 & -10781793 & 241215.97 \\
14 & 70438092.54 & 68524905 & -1913187.54 \\
15 & -462966384.8 & -447736760 & 15229624.8 \\
\hline
\end{tabular}

Base, Modified order statistic densities (of distributions) and their differences for different values of ' $\mathrm{n}$ ' and ' $\alpha$ '.

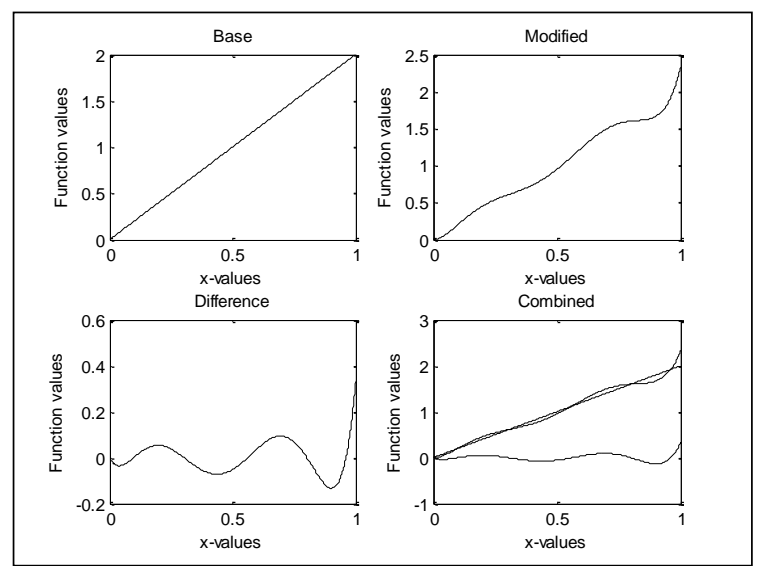

Fig. 2 (a). For the case of $\mathrm{n}=2$ and $\alpha=77.00$.

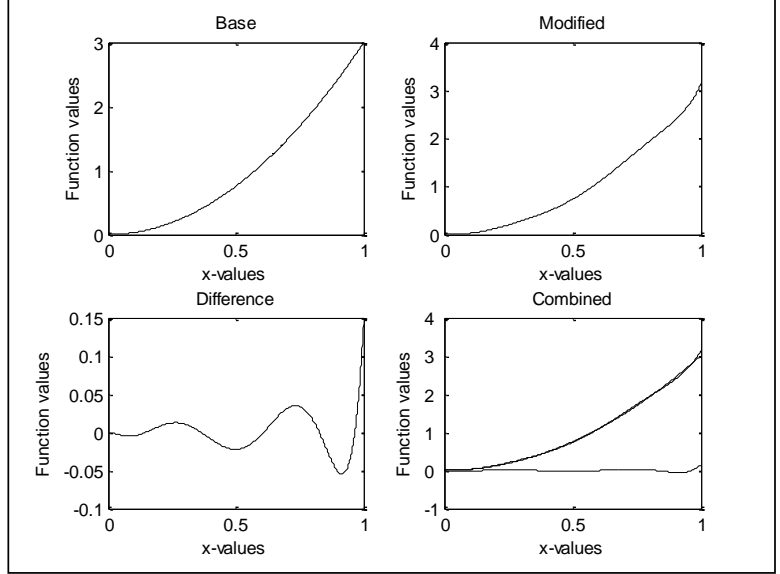

Fig. 2 (b). For the case of $n=3$ and $\alpha=37.714$.

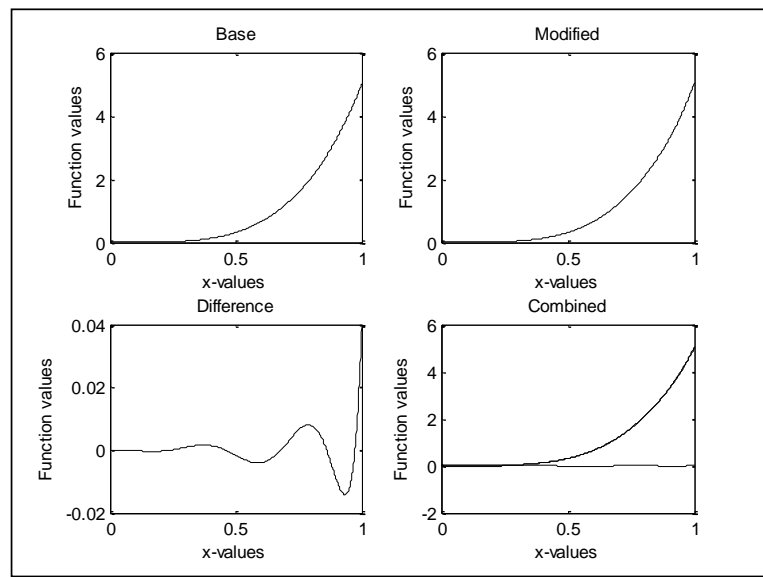

Fig. 2 (c). For the case of $\mathrm{n}=5$ and $\alpha=15.889$.

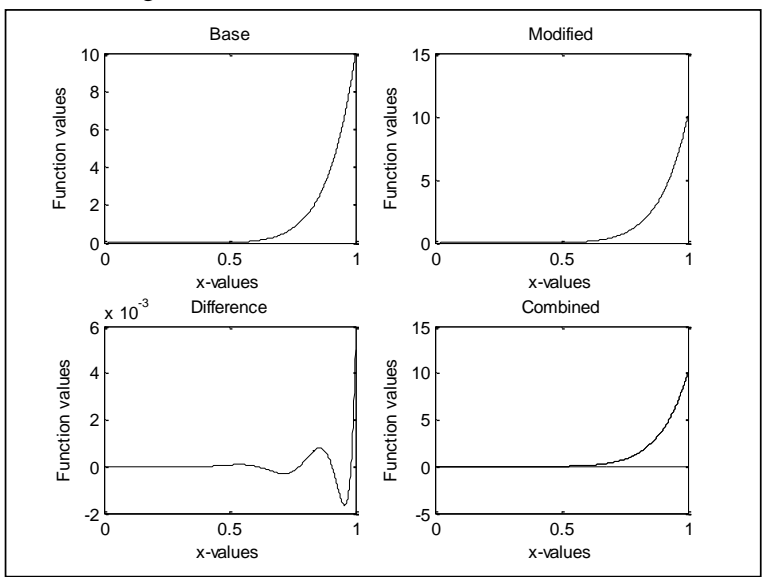

Fig. 2 (d). For the case of $\mathrm{n}=10$ and $\alpha=5.808$.

\section{Exponential Distribution}

In this section we consider the Exponential Distribution, defined by:

$$
F(x)=1-e^{-x}, 0 \leq x \leq \infty,
$$

and now the Minimum Order statistic density function of Exponential Distribution is:

$$
f_{n}(x)=n \cdot e^{-x} \cdot\left(1-\left(1-e^{-x}\right)\right)^{n-1}
$$

and Maximum Order statistic density function of Exponential Distribution is: 


$$
f_{n}(x)=n \cdot e^{-x} \cdot\left(1-e^{-x}\right)^{n-1}
$$

where ' $n$ ' is the sample size.

Now we consider the polynomials of order 5 as the modifier i.e., $\mathrm{k}=4, \mathrm{~m}=5$ (polynomial order), one gets $\mathrm{M}$, such that:

$$
\alpha \cdot \text { M. } \bar{b}=\bar{\Delta}
$$

Solving the above equation for ' $\bar{b}$, we get the modifier polynomial coefficients as ' $\bar{b}$, from which we get the following $5^{\text {th }}$ degree polynomial in ' $x$ ' with ' $n$ ', sample size.

\section{1) Minimum Order Statistics for Exponential Distribution}

The following Table VII gives the polynomials and the corresponding ' $\theta$ ' values for the chosen values of ' $n$ '.

\begin{tabular}{|c|c|c|}
\hline \multicolumn{3}{|c|}{ THE CHOSEN VALUES OF ' $N$ ' } \\
\hline $\mathrm{n}$ & $g\left(x_{\mathrm{n}}\right)$ & $\theta=\max _{\mathrm{x}}\left|g\left(x_{\mathrm{n}}\right)\right|$ \\
\hline 2 & $\begin{array}{c}(-0.740741+11.1111 * x- \\
33.3333 * x^{2}+33.3333 * x^{3}- \\
\left.12.5 * x^{4}+1.5 * x^{5}\right) * \mathrm{e}^{-x} \\
\left(-0.15625+3.125^{*} x-12.5 * x^{2}+16.66667 * x^{3}-\right.\end{array}$ & 4.6471 \\
\hline 3 & $\left.8.333 * x^{4}+\frac{4}{3} * x^{5}\right)^{*} \mathrm{e}^{-x}$ & 7.0132 \\
\hline 5 & $\begin{array}{c}(-0.018519+0.55556 * x- \\
\left.3.3333^{*} \mathrm{x}^{2}+6.66667 * x^{3}-5^{*} x^{4}+6 / 5^{*} x^{5}\right)^{*} \mathrm{e}^{-x} \\
(-0.000819+0.045079 * x-\end{array}$ & 10.35 \\
\hline 10 & $\begin{array}{c}\left.0.49587 * x^{2}+1.81818^{*} x^{3}-2.5 * x^{4}+1.1 * x^{5}\right)^{*} \\
\mathrm{e}^{-x}\end{array}$ & 14.452 \\
\hline
\end{tabular}

TABLE VII: POLYNOMIALS AND THE CORRESPONDING ' $\theta$ ' VALUES FOR

Table VIII below gives the ' $\alpha$ ' for the different ' $n$ ' and ' $\theta$ ' values.

TABLE VIII: ' $\alpha$ ' FOR THE DIFFERENT 'N' AND ' $\theta$ ' VALUES

\begin{tabular}{ccccc}
\hline $\mathrm{n}$ & 2 & 3 & 5 & 10 \\
\hline$\theta$ & 4.6471 & 7.0132 & 10.35 & 14.452 \\
$\alpha=\frac{1}{\theta}$ & 0.215188 & 0.142588 & 0.096618 & 0.069195 \\
\hline
\end{tabular}

Thus, the general formula for modified minimum order statistic distribution is:

$$
f_{m}(x)=\left(n . f(x)(1-F(x))^{n-1}\right) \cdot\left\{1+\alpha g\left(x_{\mathrm{n}}\right)\right\}
$$

Thus, for instance, when $\mathrm{n}=2$, we have:

$$
f_{\mathrm{m}}(x)=2 .\left(\mathrm{e}^{-x}\right)^{2} \cdot\left\{1+\alpha g\left(x_{\mathrm{n}}\right)\right\} \text {, and } \alpha \leq 0.215
$$

when $\mathrm{n}=3$, we have:

$$
f_{\mathrm{m}}(x)=3 .\left(\mathrm{e}^{-x}\right)^{3} \cdot\left\{1+\alpha g\left(x_{\mathrm{n}}\right)\right\} \text {, and } \alpha \leq 0.143
$$

when $\mathrm{n}=5$, we have:

$$
f_{\mathrm{m}}(x)=5 .\left(\mathrm{e}^{-x}\right)^{5} \cdot\left\{1+\alpha g\left(x_{\mathrm{n}}\right)\right\} \text {, and } \alpha \leq 0.097
$$

and, when $n=10$, we have:

$$
f_{\mathrm{m}}(x)=10 .\left(\mathrm{e}^{-x}\right)^{10} \cdot\left\{1+\alpha g\left(x_{\mathrm{n}}\right)\right\} \text {, and } \alpha \leq 0.069
$$

Similarly, $f_{\mathrm{m}}(x)$ can be computed for any value of ' $\mathrm{n}$ '.

Table IX (a), Table IX (b), Table IX (c) and Table IX (d) clearly show that the first four moments (first two moments are actual moments, i.e., mean and variance) are same for base and modified distributions and higher order moments are different.

Standardized moments for base, modified distributions and their difference.

TABLE IX (A): FOR THE CASE OF N=2 AND $\alpha=0.215188$

\begin{tabular}{cccc}
\hline Moment & Base & Modified & Difference \\
\hline 1 & 0.5 & 0.5 & 0 \\
2 & 0.25 & 0.25 & 0 \\
3 & 2 & 2 & 0 \\
4 & 9 & 9 & 0 \\
5 & 44 & 45.679281 & 1.679281 \\
6 & 265 & 295.22703 & 30.22703 \\
7 & 1854 & 2265.4234 & 411.4234 \\
8 & 14833 & 19963.383 & 5130.383 \\
9 & 133496 & 196149.89 & 62653.89 \\
10 & 1334961 & 2106603.1 & 771642.1 \\
11 & 14684570 & 24409962 & 9725392 \\
12 & 176214841 & 302620190 & 126405349 \\
13 & 2290792932 & 3992023000 & 1701230068 \\
14 & 32071101049 & 55828217000 & 23757115951 \\
15 & 481066515734 & 825604820000 & 344538304266 \\
\hline
\end{tabular}

TABLE IX (B): FOR THE CASE OF N=3 AND $\alpha=0.142588$

\begin{tabular}{cccc}
\hline Moment & Base & Modified & Difference \\
\hline 1 & 0.33333 & 0.33333 & 0 \\
2 & 0.11111 & 0.11111 & 0 \\
3 & 2 & 2 & 0 \\
4 & 9 & 9 & 0 \\
5 & 44 & 44.475836 & 0.475836 \\
6 & 265 & 274.99251 & 9.99251 \\
7 & 1854 & 2010.1328 & 156.1328 \\
8 & 14833 & 17054.665 & 2221.665 \\
9 & 133496 & 164346.58 & 30850.58 \\
10 & 1334961 & 1766011 & 431050 \\
11 & 14684570 & 20838138 & 6153568 \\
12 & 176214841 & 266702900 & 90488059 \\
13 & 2290792932 & 3667416000 & 1376623068 \\
14 & 32071101049 & 53786932000 & 21715830951 \\
15 & 481066515734 & 836629230000 & 355562714266 \\
\hline
\end{tabular}

TABLE IX (C): FOR THE CASE OF N=5 AND $\alpha=0.096618$

\begin{tabular}{cccc}
\hline Moment & Base & Modified & Difference \\
\hline 1 & 0.2 & 0.2 & 0 \\
2 & 0.04 & 0.04 & 0 \\
3 & 2 & 2 & 0 \\
4 & 9 & 9 & 0 \\
5 & 44 & 44.071907 & 0.071907 \\
6 & 265 & 266.72577 & 1.72577 \\
7 & 1854 & 1884.4527 & 30.4527 \\
8 & 14833 & 15320.019 & 487.019 \\
9 & 133496 & 141075.45 & 7579.45 \\
10 & 1334961 & 1453431.5 & 118470.5 \\
11 & 14684570 & 16574134 & 1889564 \\
12 & 176214841 & 207229800 & 31014959 \\
13 & 2290792932 & 2817091500 & 526298568 \\
14 & 32071101049 & 41326418000 & 9255316951 \\
15 & 481066515734 & 649930960000 & 168864444266 \\
\hline
\end{tabular}


TABLE IX (D): FOR THE CASE OF N=10 AND $\alpha=0.069195$

\begin{tabular}{cccc}
\hline Moment & Base & Modified & Difference \\
\hline 1 & 0.1 & 0.1 & 0 \\
2 & 0.01 & 0.01 & 0 \\
3 & 2 & 2 & 0 \\
4 & 9 & 9 & 0 \\
5 & 44 & 44.003842 & 0.003842 \\
6 & 265 & 265.10268 & 0.10268 \\
7 & 1854 & 1856.0008 & 2.0008 \\
8 & 14833 & 14868.211 & 35.211 \\
9 & 133496 & 134097.72 & 601.72 \\
10 & 1334961 & 1345274 & 10313 \\
11 & 14684570 & 14864764 & 180194 \\
12 & 176214841 & 179452590 & 3237749 \\
13 & 2290792932 & 2350905400 & 60112468 \\
14 & 32071101049 & 33227220000 & 1156118951 \\
15 & 481066515734 & 504127830000 & 23061314266 \\
\hline
\end{tabular}

Base, Modified densities (of distributions) and their differences for different values of ' $n$ ' and ' $\alpha$ '.
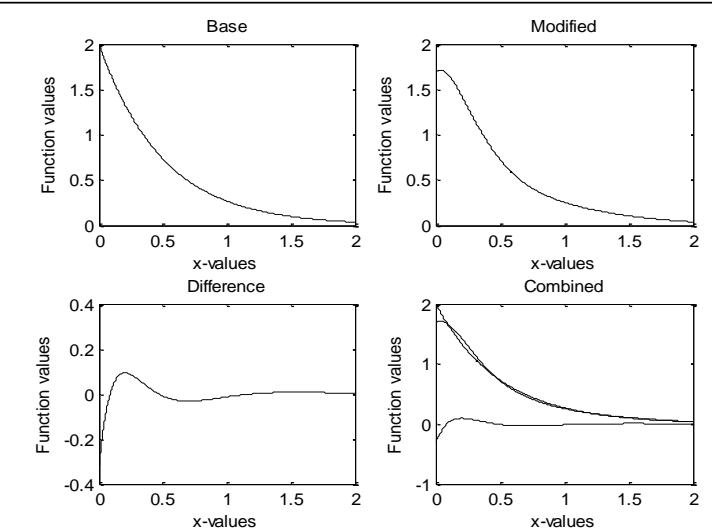

Fig. 3 (a). For the case of $\mathrm{n}=2$ and $\alpha=0.215188$.

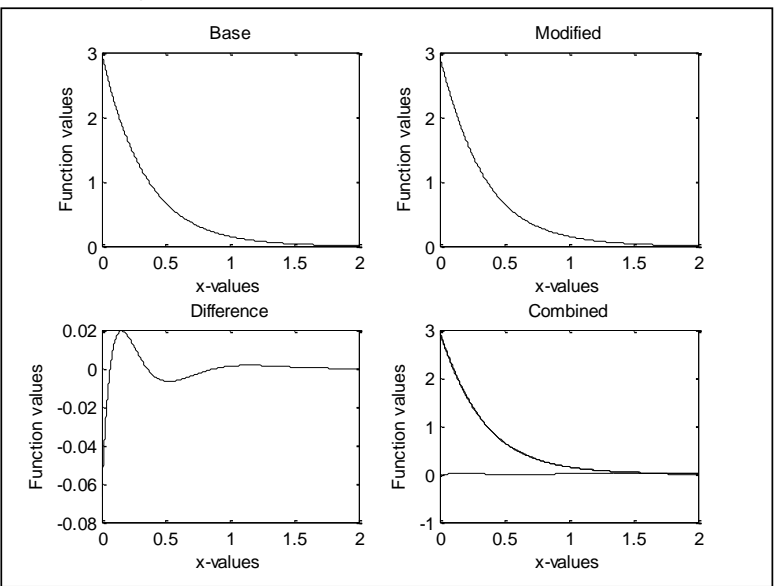

Fig. 3(b). For the case of $\mathrm{n}=3$ and $\alpha=0.142588$.

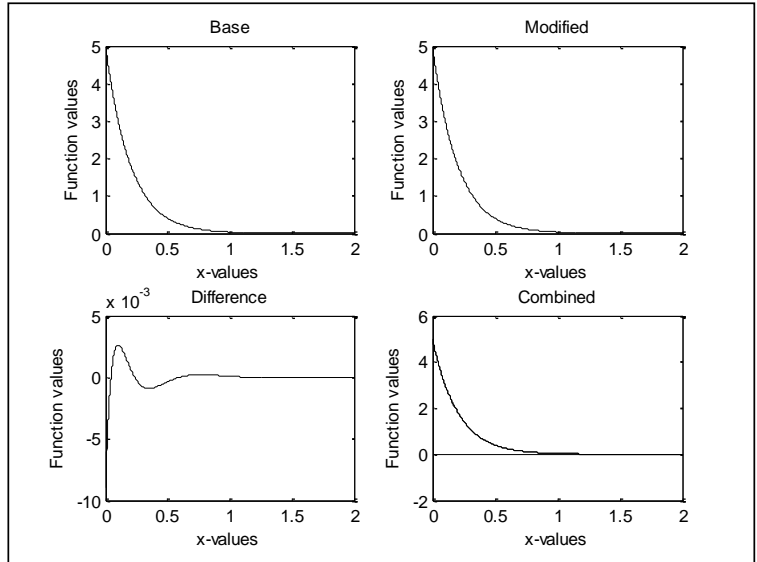

Fig. 3 (c). For the case of $\mathrm{n}=5$ and $\alpha=0.096618$.

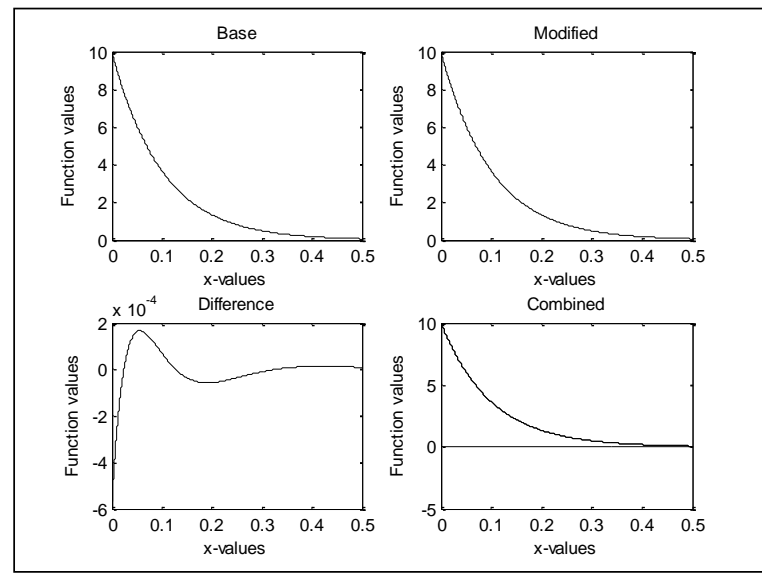

Fig. 3 (d). For the case of $\mathrm{n}=10$ and $\alpha=0.069195$.

2) Maximum Order Statistics for Exponential Distribution

The following Table $\mathrm{X}$ gives the polynomials and the corresponding ' $\theta$ ' values for the chosen values of ' $n$ '.

TABLE X: POLYNOMIALS AND THE CORRESPONDING ' $\theta$ ' VALUES FOR THE CHOSEN VALUES OF ' $\mathrm{N}$ '

\begin{tabular}{|c|c|c|}
\hline $\mathrm{n}$ & $g\left(x_{\mathrm{n}}\right)$ & $\theta=\max _{\mathrm{x}} \mid g\left(x_{\mathrm{n}}\right)$ \\
\hline 2 & $\begin{array}{c}3 .(-12.118258+70.011972 * x- \\
106.67163 * x^{2}+60.315411 * x^{3}- \\
\left.13.510848 * x^{4}+x^{5}\right) * \mathrm{e}^{-x}\end{array}$ & 36.35438 \\
\hline 3 & $\begin{array}{l}\text { 4. }\left(-24.891753+108.11083^{*} x-\right. \\
138.35147 * x^{2}+69.608755^{*} x^{3}- \\
\left.14.356954 * x^{4}+x^{5}\right)^{*} \mathrm{e}^{-x}\end{array}$ & 99.55202 \\
\hline 5 & $\begin{array}{c}\text { 6.(-61.624876+194.79038*x- } \\
200.01646^{*} x^{2}+85.819686^{*} x^{3}- \\
\left.15.719125^{*} x^{4}+x^{5}\right)^{*} \mathrm{e}^{-x}\end{array}$ & 369.68577 \\
\hline 10 & $\begin{array}{l}11 .(-198.066606+437.644659 * x- \\
340.320795 * x^{2}+117.346555^{*} x^{3}- \\
\left.18.067320 * x^{4}+x^{5}\right)^{*} \mathrm{e}^{-x}\end{array}$ & 2183.40611 \\
\hline
\end{tabular}

Table XI below gives the ' $\alpha$ ' for the different ' $\mathrm{n}$ ' and ' $\theta$ 'values.

TABLE XI: ' $\alpha$ ' FOR THE DIFFERENT 'N' AND ' $\theta$ ' VALUES

\begin{tabular}{ccccc}
\hline $\mathrm{n}$ & 2 & 3 & 5 & 10 \\
\hline$\theta$ & 36.35438 & 99.55202 & 369.68577 & 2183.40611 \\
$\alpha=\frac{1}{\theta}$ & 0.027507 & 0.010045 & 0.002705 & 0.000458
\end{tabular}

Thus, the general formula for modified maximum order statistic distribution is:

$$
f_{m}(x)=\left(n \cdot f(x) F(x)^{n-1}\right) \cdot\left\{1+\alpha g\left(x_{\mathrm{n}}\right)\right\}
$$

Thus, for instance, when $\mathrm{n}=2$, we have:

$$
f_{\mathrm{m}}(x)=2 \mathrm{e}^{-x}\left(1-\mathrm{e}^{-x}\right) \cdot\left\{1+\alpha g\left(x_{\mathrm{n}}\right)\right\} \text {, and } \alpha \leq 0.028
$$

When $\mathrm{n}=3$, we have:

$$
f_{\mathrm{m}}(x)=3 \mathrm{e}^{-x}\left(1-\mathrm{e}^{-x}\right)^{2} \cdot\left\{1+\alpha g\left(x_{\mathrm{n}}\right)\right\} \text {, and } \alpha \leq 0.010
$$

When $\mathrm{n}=5$, we have:

$$
f_{\mathrm{m}}(x)=5 \mathrm{e}^{-x}\left(1-\mathrm{e}^{-x}\right)^{4} \cdot\left\{1+\alpha g\left(x_{\mathrm{n}}\right)\right\} \text {, and } \alpha \leq 0.003
$$

And, when $\mathrm{n}=10$, we have: 


$$
f_{\mathrm{m}}(x)=10 \mathrm{e}^{-x}\left(1-\mathrm{e}^{-x}\right)^{9} \cdot\left\{1+\alpha g\left(x_{\mathrm{n}}\right)\right\} \text {, and } \alpha \leq 0.001
$$

Similarly, $f_{\mathrm{m}}(x)$ can be computed for any value of ' $\mathrm{n}$ '.

Table XII (a), Table XII (b), Table XII (c) and Table XII (d) clearly show that the first four moments (first two moments are actual moments, i.e., mean and variance) are same for base and modified distributions and higher order moments are different.

Standardized moments for base, modified distributions and their differences are:

TABLE XII (A): FOR THE CASE OF N=2 AND $\alpha=0.027507$

\begin{tabular}{cccc}
\hline Moment & Base & Modified & Difference \\
\hline 1 & 1.5 & 1.5 & 0 \\
2 & 1.25 & 1.25 & 0 \\
3 & 1.6099683 & 1.6099683 & 0 \\
4 & 7.08 & 7.08 & 0 \\
5 & 30.267416 & 30.709885 & 0.442469 \\
6 & 164.52 & 168.52689 & 4.00689 \\
7 & 1028.770155 & 1061.2672 & 32.49704491 \\
8 & 7367.1696 & 7615.731 & 248.5614 \\
9 & 59314.19247 & 61222.024 & 1907.831527 \\
10 & 530584.1885 & 545557.0800 & 14972.89152 \\
11 & 5220537.447 & 5341970.200 & 121432.7527 \\
12 & 56034220.46 & 57057003.00 & 1022782.539 \\
13 & 651549760.6 & 660517250.0 & 8967489.408 \\
14 & 8158749077 & 8240666500 & 81917423 \\
15 & 109461477958 & 110241150000 & 779672042 \\
\hline
\end{tabular}

TABLE XII (B): FOR THE CASE OF N=3 AND $\alpha=0.010045$

\begin{tabular}{cccc}
\hline Moment & Base & Modified & Difference \\
\hline 1 & 1.8333333 & 1.8333333 & 0 \\
2 & 1.361111 & 1.361111 & 0 \\
3 & 1.463557 & 1.463557 & 0 \\
4 & 6.4810505 & 6.4810505 & 0 \\
5 & 26.13220682 & 26.31818 & 0.1859732 \\
6 & 137.0329115 & 138.47994 & 1.4470285 \\
7 & 820.1818071 & 831.17275 & 10.990943 \\
8 & 5631.675868 & 5710.0885 & 78.412632 \\
9 & 43452.37273 & 44019.32 & 566.94727 \\
10 & 372510.0000 & 376718.5100 & 4203.9686 \\
11 & 3512543.381 & 3544848.300 & 32304.919 \\
12 & 36130441.43 & 36388731.00 & 258289.57 \\
13 & 402604180.1 & 404757060.0 & 2152879.9 \\
14 & 4831297319 & 4850014700 & 18717381 \\
15 & 62116982775 & 62286692000 & 169709225 \\
\hline
\end{tabular}

TABLE XII (C): FOR THE CASE OF N=5 AND $\alpha=0.002705$

\begin{tabular}{cccc}
\hline Moment & Base & Modified & Difference \\
\hline 1 & 2.2833333 & 2.2833333 & 0 \\
2 & 1.4636111 & 1.4636111 & 0 \\
3 & 1.3392214 & 1.3392214 & 0 \\
4 & 6.0259736 & 6.0259736 & 0 \\
5 & 22.992498 & 23.052957 & 0.060459 \\
6 & 117.26109 & 117.65746 & 0.39637 \\
7 & 675.46393 & 678.33678 & 2.87285 \\
8 & 4476.1153 & 4495.2478 & 19.1325 \\
9 & 33303.3457 & 33434.589 & 131.2433 \\
10 & 275348.172 & 276272.53 & 924.358 \\
11 & 2503811.626 & 2510581.7 & 6770.074 \\
12 & 24836602.29 & 24888285 & 51682.71 \\
13 & 266890678 & 267302610 & 411932.03 \\
14 & 3088545498 & 3091974100 & 3428602.4 \\
15 & 38294386225 & 38324173000 & 29786775 \\
\hline
\end{tabular}

TABLE XII (D): FoR THE CASE OF N=10 AND $\alpha=0.000458$

\begin{tabular}{cccc}
\hline Moment & Base & Modified & Difference \\
\hline 1 & 2.9289684 & 2.9289684 & 0 \\
2 & 1.5497678 & 1.5497678 & 0 \\
3 & 1.2414152 & 1.2414152 & 0 \\
4 & 5.7030856 & 5.7030856 & 0 \\
5 & 20.737247 & 20.749936 & 0.012689 \\
6 & 103.75549 & 103.82458 & 0.06909 \\
7 & 579.26026 & 579.75352 & 0.49326 \\
8 & 3734.1203 & 3737.1865 & 3.0662 \\
9 & 26995.359 & 27015.562 & 20.203 \\
10 & 216920.36 & 217056.47 & 136.11 \\
11 & 1916913.2 & 1917871.4 & 958.2 \\
12 & 18478948.5 & 18485987 & 7038.5 \\
13 & 192974445.5 & 193028510 & 54064.53 \\
14 & 2170205882 & 2170639800 & 433918.04 \\
15 & 26149420508 & 26153057000 & 3636492.3 \\
\hline
\end{tabular}

Base, Modified densities (of distributions) and their differences for different values of ' $n$ ' and ' $\alpha$.
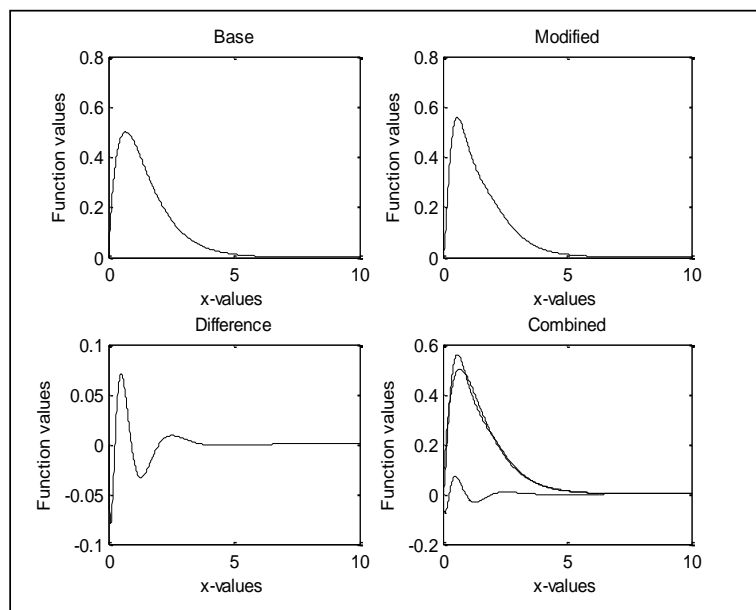

Fig. 4 (a). For the case of $\mathrm{n}=2$ and $\alpha=0.027507$.

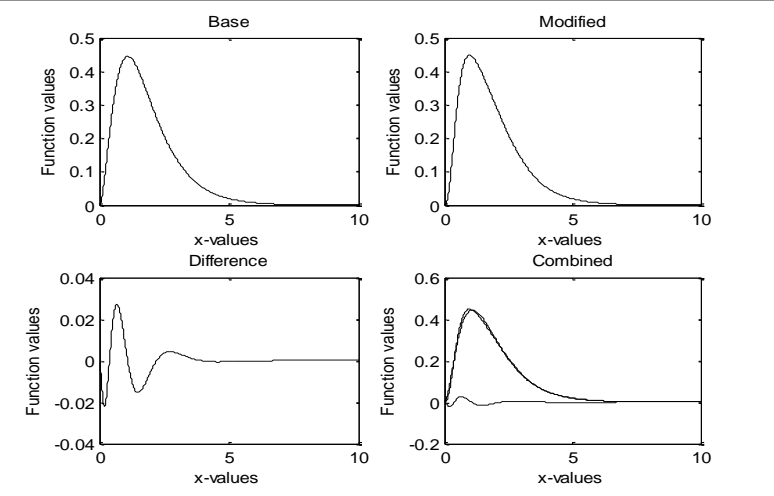

Fig. 4 (b). For the case of $n=3$ and $\alpha=0.010045$.

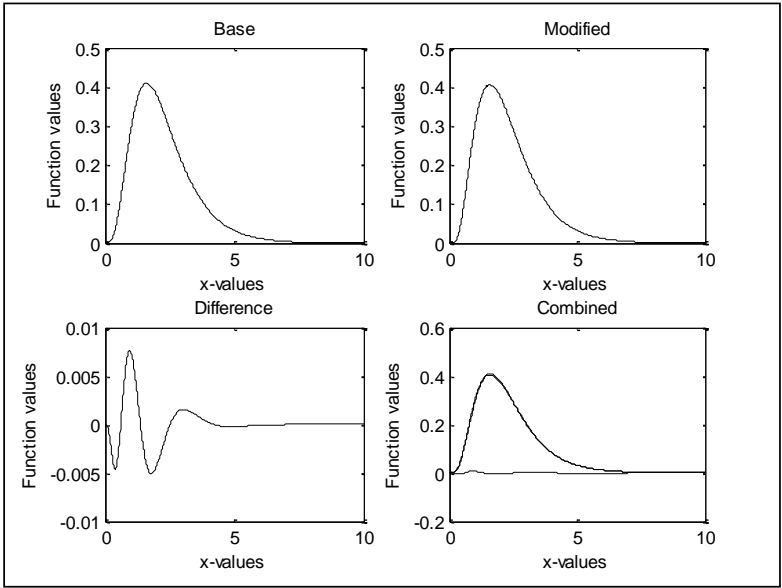

Fig .4 (c). For the case of $\mathrm{n}=5$ and $\alpha=0.002705$. 


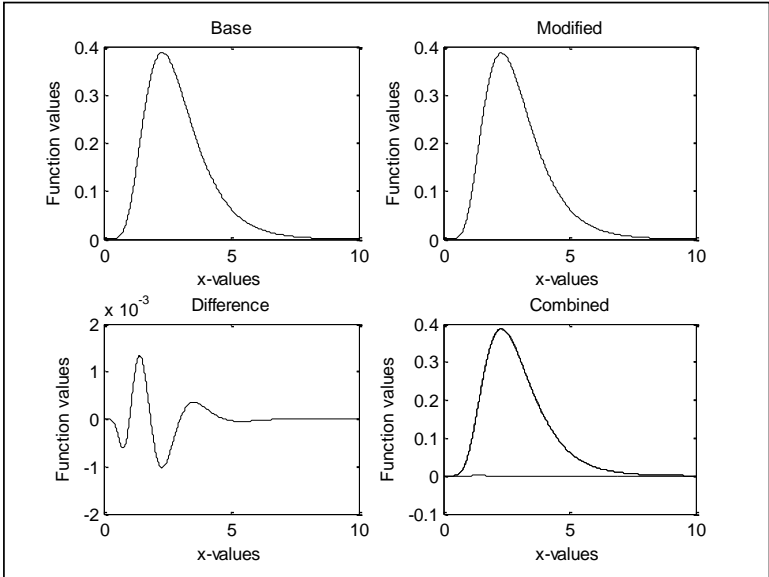

Fig. 4 (d). For the case of $\mathrm{n}=10$ and $\alpha=0.000458$.

\section{Gamma Distribution}

Here we consider the Gamma Distribution, defined by:

$$
\begin{gathered}
f(x)=\frac{1}{[b \cdot \Gamma(c)]} \cdot\left[\frac{x}{b}\right]^{c-1} \cdot e^{-\frac{x}{b}} \text { for } 0 \leq x \leq \infty \text { and } c>0 . \\
F(x)=1-(1+x) e^{-x}, 0 \leq x \leq \infty,
\end{gathered}
$$

where shape parameter $(c)=2$ and scale parameter $(b)=1$.

Minimum Order statistic distribution function of Gamma Distribution is:

$$
f_{n}(x)=n \cdot x \cdot e^{-x} \cdot\left((1+x) e^{-x}\right)^{n-1}
$$

and Maximum Order statistic distribution function of Gamma Distribution is:

$$
f_{n}(x)=n \cdot x \cdot e^{-x} \cdot\left(1-(1+x) e^{-x}\right)^{n-1}
$$

where ' $n$ ' is the sample size.

Now we consider the polynomials of order 5 as the modifier i.e. $\mathrm{k}=4, \mathrm{~m}=5$ (polynomial order), one gets $\mathrm{M}$, such that:

$$
\alpha \text {.M. } \bar{b}=\bar{\Delta}
$$

Solving the above equation for $\bar{b}$, we get the modifier polynomial coefficients as $\bar{b}$, from which we get the following $5^{\text {th }}$ degree polynomial in ' $x$ ' with ' $n$ ', sample size.

\section{1) Minimum Order Statistics for Gamma Distribution}

The following Table XIII gives the polynomials and the corresponding ' $\theta$ ' values for the chosen values of ' $n$ '.

Table XIV below gives the ' $\alpha$ ' for the different ' $n$ ' and ' $\theta$ ' values.

Thus, the general formula for modified minimum order statistic distribution is:

$$
f_{m}(x)=\left(n . f(x)(1-F(x))^{n-1}\right) .\{1+\alpha \mathrm{g}(\mathrm{xn})\}
$$

Thus, for instance, when $\mathrm{n}=2$, we have:

$\mathrm{fm}(\mathrm{x})=2 \cdot \mathrm{x} \cdot(1+\mathrm{x}) \cdot(\mathrm{e}-\mathrm{x}) 2 \cdot\{1+\alpha \mathrm{g}(\mathrm{xn})\}$, and $\alpha \leq 0.072$

$$
\mathrm{fm}(\mathrm{x})=3 \cdot \mathrm{x} \cdot(1+\mathrm{x}) 2 \cdot(\mathrm{e}-\mathrm{x}) 3 \cdot\{1+\alpha \mathrm{g}(\mathrm{xn})\} \text {, and } \alpha \leq 0.151
$$

\begin{tabular}{|c|c|c|}
\hline $\mathrm{n}$ & $g\left(x_{n}\right)$ & $\theta=\max _{\mathrm{x}}\left|g\left(x_{n}\right)\right|$ \\
\hline 2 & $\begin{array}{c}(-13.992850+90.939227 * x- \\
160.83198 * x^{2}+108.25154 * x^{3}- \\
\left.29.47741 * x^{4}+2.7 * x^{5}\right)^{*} \mathrm{e}^{-x} \\
(-4.234567+33.041736 * x-\end{array}$ & 13.99286 \\
\hline 3 & $\begin{array}{l}71.020412 * x^{2}+58.630829 * x^{3}- \\
\left.19.725296 * x^{4}+128 / 57 * x^{5}\right)^{*} \mathrm{e}^{-x} \\
(-0880615+8.84918 * x-\end{array}$ & 6.627652 \\
\hline 5 & $\begin{array}{c}\left(-0.880615+8.84918^{*} x-\right. \\
24.85252 * x^{2}+27.10948^{*} x^{3}- \\
\left.12.1614 * x^{4}+1944 / 1045 * x^{5}\right)^{*} \mathrm{e}^{-x}\end{array}$ & 9.513843 \\
\hline 10 & $\begin{array}{c}\left(-0.10085+1.46378^{*} x-\right. \\
6.03795^{*} x^{2}+9.8036^{*} x^{3}- \\
\left.6.61987^{*} x^{4}+928 / 603^{*} x^{5}\right)^{*} \mathrm{e}^{-x}\end{array}$ & 13.13267 \\
\hline
\end{tabular}

When $\mathrm{n}=5$, we have:

$\mathrm{fm}(\mathrm{x})=4 \cdot \mathrm{x} \cdot(1+\mathrm{x}) 4 \cdot(\mathrm{e}-\mathrm{x}) 4 \cdot\{1+\alpha \mathrm{g}(\mathrm{xn})\}$, and $\alpha \leq 0.105$

And, when $\mathrm{n}=10$, we have:

$$
\begin{gathered}
\mathrm{fm}(\mathrm{x})=10 \cdot \mathrm{x} \cdot(1+\mathrm{x}) 9 \cdot(\mathrm{e}-\mathrm{x}) 10 \cdot\{1+\alpha \mathrm{g}(\mathrm{xn})\}, \text { and } \alpha \leq \\
0.076
\end{gathered}
$$

TABLE XIII: POLYNOMIALS AND THE CORRESPONDING ' $\theta$ ' VALUES FOR THE CHOSEN VALUES OF ' $N$ '

\begin{tabular}{ccccc}
\multicolumn{4}{c}{ TABLE XIV: ‘ $\alpha$ ' FOR THE DIFFERENT 'N' AND ‘ $\theta$ ' VALUES } \\
\hline $\mathrm{n}$ & 2 & 3 & 5 & 10 \\
\hline$\theta$ & 13.9928 & 6.627652 & 9.513843 & 13.13267 \\
$\alpha=\frac{1}{\theta}$ & 0.07147 & 0.15088 & 0.10 .511 & 0.07615 \\
\hline
\end{tabular}

Similarly, fm(x) can be computed for any value of ' $n$ '.

Table XV (a), Table XV (b), Table XV (c) and Table XV (d) clearly show that the first four moments are same for base and modified distributions and higher order moments are different.

Standardized moments for base, modified distributions and their difference.

TABLE XV (A): FOR THE CASE OF N=2 AND $\alpha=0.072$

\begin{tabular}{cccc}
\hline Moment & Base & Modified & Difference \\
\hline 1 & 1.25 & 1.25 & 0 \\
2 & 0.6875 & 0.6875 & 0 \\
3 & 1.260866 & 1.260866 & 0 \\
4 & 5.330579 & 5.330579 & 0 \\
5 & 18.290027 & 18.943591 & 0.653564 \\
6 & 83.076634 & 89.101117 & 6.024483 \\
7 & 417.01669 & 466.74904 & 49.73235 \\
8 & 2377.01421 & 2760.4959 & 383.48169 \\
9 & 15015.669 & 17965.593 & 2949.924 \\
10 & 104285.556 & 127350.3 & 23064.744 \\
11 & 789105.27 & 974504.23 & 185398.96 \\
12 & 6460188.8 & 8000625.5 & 1540436.7 \\
13 & 56879071.2 & 70146228 & 13267156.8 \\
14 & 535843756.8 & 654434810 & 118591053.2 \\
15 & 5377495920 & 6478080300 & 1100584380 \\
\hline
\end{tabular}

When $\mathrm{n}=3$, we have: 
TABLE XV (B): FOR THE CASE OF N=3 AND $\alpha=0.151$

\begin{tabular}{cccc}
\hline Moment & Base & Modified & Difference \\
\hline 1 & 0.9629628 & 0.9629628 & 0 \\
2 & 0.38134424 & 0.38134424 & 0 \\
3 & 1.176221 & 1.176221 & 0 \\
4 & 4.98639 & 4.98639 & 0 \\
5 & 16.134377 & 16.8228 & 0.688423 \\
6 & 70.52204 & 77.57436 & 7.05232 \\
7 & 335.6914 & 398.18257 & 62.49117 \\
8 & 1814.3911 & 2329.3622 & 514.9711 \\
9 & 10822.144 & 15029.027 & 4206.883 \\
10 & 70787.71 & 105583.05 & 34795.34 \\
11 & 503159.22 & 798066.49 & 294907.27 \\
12 & 3860720.03 & 6437452.8 & 2576732.77 \\
13 & 31792784.9 & 55076923 & 23284138.1 \\
14 & 279607410 & 497543700 & 217936290 \\
15 & 2615021648 & 4729167300 & 2114145652 \\
\hline
\end{tabular}

TABLE XV (C): For THE CASE OF N=5 AND $\alpha=0.105$

\begin{tabular}{cccc}
\hline Moment & Base & Modified & Difference \\
\hline 1 & 0.70208 & 0.70208 & 0 \\
2 & 0.18791567 & 0.18791567 & 0 \\
3 & 1.078873 & 1.078873 & 0 \\
4 & 4.613901 & 4.613901 & 0 \\
5 & 13.860755 & 14.00737 & 0.146615 \\
6 & 57.970922 & 59.565719 & 1.594797 \\
7 & 258.32116 & 273.01114 & 14.68998 \\
8 & 1308.6773 & 1433.8007 & 125.1234 \\
9 & 7270.795 & 8321.3844 & 1050.5894 \\
10 & 44154.443 & 53048.397 & 8893.954 \\
11 & 290327.63 & 367206.64 & 76879.01 \\
12 & 2054238.799 & 2737203.3 & 682964.501 \\
13 & 15553883.1 & 21811461 & 6257577.905 \\
14 & 125434973.7 & 184676320 & 59241346.3 \\
15 & 1073059488 & 1653035100 & 579975612 \\
\hline
\end{tabular}

TABLE XV (D): FOR THE CASE OF N=10 AND $\alpha=0.076$

\begin{tabular}{cccc}
\hline Moment & Base & Modified & Difference \\
\hline 1 & 0.46602157 & 0.46602157 & 0 \\
2 & 0.076028 & 0.076028 & 0 \\
3 & 0.966763 & 0.966763 & 0 \\
4 & 4.217005 & 4.217005 & 0 \\
5 & 11.506425 & 11.521712 & 0.015287 \\
6 & 45.82875 & 45.995427 & 0.166677 \\
7 & 187.85691 & 189.38412 & 1.52721 \\
8 & 879.62922 & 892.48367 & 12.85445 \\
9 & 4472.8236 & 4578.9275 & 106.1039 \\
10 & 24762.446 & 25641.319 & 878.873 \\
11 & 147654.587 & 155056.45 & 7401.863 \\
12 & 943290.544 & 1007110.7 & 63820.156 \\
13 & 6421606.76 & 6987126.9 & 565520.14 \\
14 & 46381439.91 & 51542227 & 5160787.09 \\
15 & 354066308 & 402618920 & 48552612 \\
\hline
\end{tabular}

Base, Modified densities (of distributions) and their differences for different values of ' $\mathrm{n}$ ' and ' $\alpha$ '.
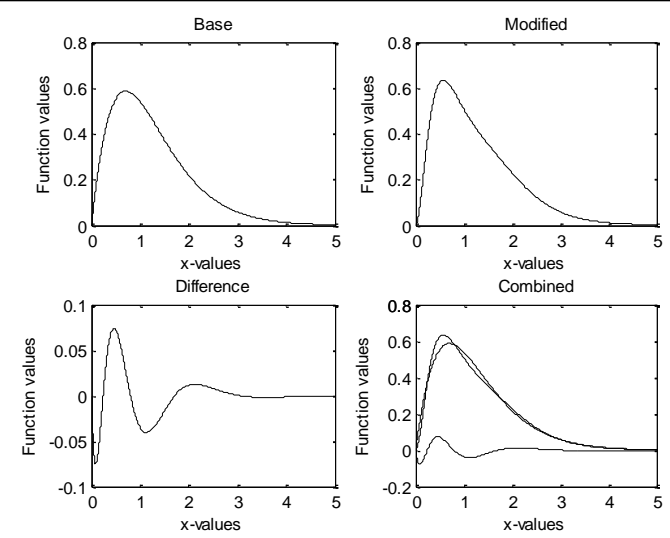

Fig. 5 (a). For the case of $\mathrm{n}=2$ and $\alpha=0.072$.

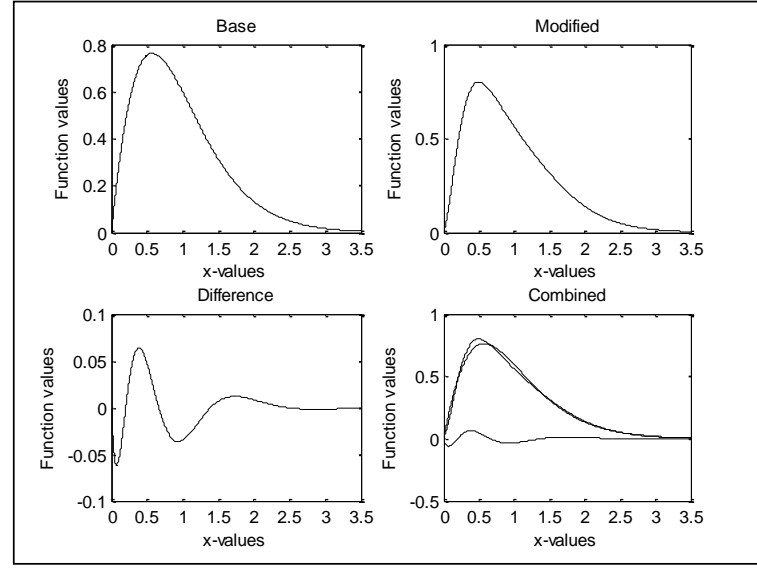

Fig. 5 (b). For the case of $\mathrm{n}=3$ and $\alpha=0.151$.

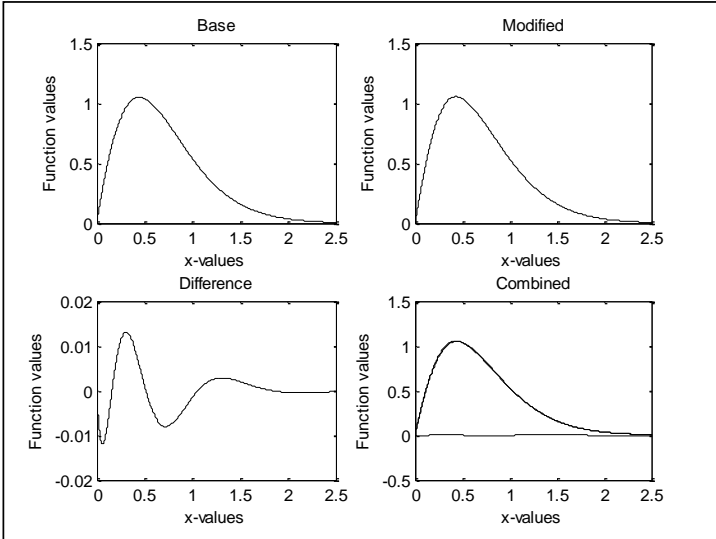

Fig. 5 (c). For the case of $n=5$ and $\alpha=0.105$.

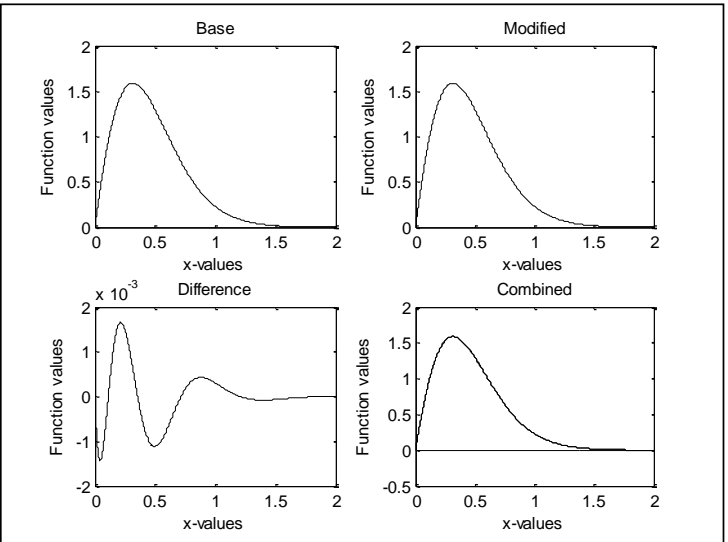

Fig. 5 (d). For the case of $n=10$ and $\alpha=0.076$.

\section{2) Maximum Order Statistics for Gamma Distribution}

The following Table XVI gives the polynomials and the corresponding ' $\theta$ ' values for the chosen values of ' $n$ '.

TABLE XVI: POLYNOMIALS AND THE CORRESPONDING ' $\theta$ ' VALUES FOR THE CHOSEN VALUES OF ' $N$ '

\begin{tabular}{ccc}
\hline $\mathrm{n}$ & $g\left(x_{n}\right)$ & $\theta=\max _{\mathrm{x}}\left|g\left(x_{n}\right)\right|$ \\
\cline { 2 - 3 } 2 & $(-643.09026+1972.0058 * x-$ & \\
& $1916.1244 * x^{2}+768.20953 * x^{3}-$ & 643.0868 \\
& $\left.130.73209 * x^{4}+54 / 7 * x^{5}\right) * \mathrm{e}^{-x}$ & \\
& $(-2114.6917+5072.1983 * x-$ & \\
3 & $4108.7548 * x^{2}+1434.1843 * x^{3}-$ & 2114.1649 \\
& $\left.219.14792 * x^{4}+1152 / 97 * x^{5}\right) * \mathrm{e}^{-x}$ & \\
& $(-9322.2623+17118.467 * x-$ & \\
5 & $11202.126 * x^{2}+3291.2109 * x^{3}-$ & \\
& $\left.437.05601 * x^{4}+3673 / 174 * x^{5}\right) * \mathrm{e}^{-x}$ & \\
& $(-63276.988+86530.723 * x-$ & \\
10 & $44013.615 * x^{2}+10424.002 * x^{3}-$ & \\
& $\left.1151.0504 * x^{4}+4747 / 100 * x^{5}\right) * \mathrm{e}^{-x}$ & \\
& &
\end{tabular}


Table XVII7 below gives the ' $\alpha$ ' for the different ' $\mathrm{n}$ ' and ' $\theta$ ' values.

TABLE XVII: ' $\alpha$ ' FOR THE DIFFERENT 'N' AND ‘ $\theta$ ' VALUES

\begin{tabular}{ccccc}
\hline $\mathrm{n}$ & 2 & 3 & 5 & 10 \\
\hline$\theta$ & $\begin{array}{c}643.086 \\
8\end{array}$ & 2114.1649 & 9345.794 & 62500 \\
$\alpha=\frac{1}{\theta}$ & $\begin{array}{c}0.00155 \\
5\end{array}$ & 0.000473 & 0.000107 & 0.000016 \\
\hline
\end{tabular}

Thus, the general formula for modified minimum order statistic distribution is:

$$
f_{m}(x)=\left(n . f(x) F(x)^{n-1}\right) \cdot\left\{1+\alpha g\left(x_{n}\right)\right\}
$$

Thus, for instance, when $\mathrm{n}=2$, we have:

$f_{\mathrm{m}}(x)=x \cdot\left(2-2 \cdot(1+x) \cdot \mathrm{e}^{-x}\right) \cdot \mathrm{e}^{-x} \cdot\left\{1+\alpha g\left(x_{n}\right)\right\}$, and $\alpha \leq 0.0016$

When $\mathrm{n}=3$, we have:

$$
f_{\mathrm{m}}(x)=3 \cdot x \cdot\left(2-2 \cdot(1+x) \cdot \mathrm{e}^{-x}\right)^{2} \cdot \mathrm{e}^{-x} \cdot\left\{1+\alpha g\left(x_{n}\right)\right\}
$$

and $\alpha \leq 0.0005$.

When $\mathrm{n}=5$, we have:

$$
f_{\mathrm{m}}(x)=5 \cdot x \cdot\left(2-2 \cdot(1+x) \cdot \mathrm{e}^{-x}\right)^{4} \cdot \mathrm{e}^{-x} \cdot\left\{1+\alpha g\left(x_{n}\right)\right\},
$$

and $\alpha \leq 0.0001 /$

And, when $\mathrm{n}=10$, we have:

$$
f_{\mathrm{m}}(x)=10 \cdot x \cdot\left(2-2 \cdot(1+x) \cdot \mathrm{e}^{-x}\right)^{9} \cdot \mathrm{e}^{-x} \cdot\left\{1+\alpha g\left(x_{n}\right)\right\},
$$

and $\alpha \leq 0.00002$.

Similarly, $f_{\mathrm{m}}(x)$ can be computed for any value of ' $n$ '.

Table XVIII (a), Table XVIII (b), Table XVIII (c) and Table XVIII (d) clearly show that the first four moments are same for base and modified distributions and higher order moments are different.

Standardized moments for base, modified distributions and their difference.

\begin{tabular}{|c|c|c|c|}
\hline Moment & Base & Modified & Difference \\
\hline 1 & 3.2129629 & 3.2129629 & 0 \\
\hline 2 & 2.2355109 & 2.2355109 & 0 \\
\hline 3 & 1.138663 & 1.138663 & 0 \\
\hline 4 & 5.168295 & 5.168295 & 0 \\
\hline 5 & 17.154259 & 17.167078 & 0.012819 \\
\hline 6 & 79.991832 & 80.040186 & 0.048354 \\
\hline 7 & 406.573367 & 406.89741 & 0.324043 \\
\hline 8 & 2379.5459 & 2381.1881 & 1.6422 \\
\hline 9 & 15489.83831 & 15499.271 & 9.43269 \\
\hline 10 & 111486.559 & 111540.71 & 54.151 \\
\hline 11 & 877988.787 & 878317.02 & 328.233 \\
\hline 12 & 7510346.957 & 7512417.4 & 2070.443 \\
\hline 13 & 69329994.62 & 69343668 & 13673.38 \\
\hline 14 & 686899076.4 & 686993440 & 94363.57 \\
\hline 15 & 7269644378 & 7270324800 & 680422.02 \\
\hline \multicolumn{4}{|c|}{ TABLE XVIII (C): FOR THE CASE OF N=5 AND $\alpha=0.0001$} \\
\hline Moment & Base & Modified & Difference \\
\hline 1 & 3.8082722 & 3.8082722 & 0 \\
\hline 2 & 2.2525964 & 2.2525964 & 0 \\
\hline 3 & 1.087835 & 1.087835 & 0 \\
\hline 4 & 5.056374 & 5.056374 & 0 \\
\hline 5 & 16.345891 & 16.349486 & 0.003595 \\
\hline 6 & 76.167268 & 76.178468 & 0.0112 \\
\hline 7 & 382.66238 & 382.74398 & 0.0816 \\
\hline 8 & 2224.767 & 2225.1507 & 0.3837 \\
\hline 9 & 14372.845 & 14375.065 & 2.22 \\
\hline 10 & 102755.895 & 102768.3 & 12.405 \\
\hline 11 & 804026.319 & 804100.77 & 74.451 \\
\hline 12 & 6835741.564 & 6836204.3 & 462.736 \\
\hline 13 & 62733720.55 & 62736740 & 3019.45 \\
\hline 14 & 618049268.7 & 618069850 & 20581.3 \\
\hline 15 & 6505409604 & 6505556200 & 146595.82 \\
\hline
\end{tabular}

TABLE XVIII (A): FOR THE CASE OF N $=2$ AND $\alpha=0.0016$

\begin{tabular}{cccc}
\hline Moment & Base & Modified & Difference \\
\hline 1 & 2.75 & 2.75 & 0 \\
2 & 2.1875 & 2.1875 & 0 \\
3 & 1.207363 & 1.207363 & 0 \\
4 & 5.346123 & 5.346123 & 0 \\
5 & 18.369031 & 18.403152 & 0.034121 \\
6 & 86.194169 & 86.348606 & 0.154437 \\
7 & 446.0136 & 447.00664 & 0.99304 \\
8 & 2644.81 & 2650.1859 & 5.3759 \\
9 & 17459.6821 & 17490.941 & 31.2589 \\
10 & 127343.1851 & 127527.99 & 184.8049 \\
11 & 1016041.658 & 1017184 & 1142.342 \\
12 & 8802954.783 & 8810310.8 & 7356.017 \\
13 & 82289021.72 & 82338496 & 49474.277 \\
14 & 825438593.9 & 825785990 & 347396.1 \\
15 & 8843163318 & 8845708300 & 2544982.1 \\
\hline
\end{tabular}

TABLE XVIII (B): FOR THE CASE OF N $=3$ AND $\alpha=0.0005$

TABLE XVIII (D): FOR THE CASE OF N $=10$ AND $\alpha=0.00002$

\begin{tabular}{cccc}
\hline Moment & Base & Modified & Difference \\
\hline 1 & 4.622957 & 4.622957 & 0 \\
2 & 2.2313893 & 2.2313893 & 0 \\
3 & 1.058087 & 1.058087 & 0 \\
4 & 5.010669 & 5.010669 & 0 \\
5 & 15.969113 & 15.969751 & 0.000638 \\
6 & 74.717092 & 74.718782 & 0.00169 \\
7 & 374.102919 & 374.11657 & 0.013651 \\
8 & 2176.49748 & 2176.5576 & 0.06012 \\
9 & 14063.289 & 14063.646 & 0.357 \\
10 & 100650.878 & 100652.84 & 1.962 \\
11 & 788672.57 & 788684.42 & 11.85 \\
12 & 6717437.33 & 6717511.1 & 73.77 \\
13 & 61779618.47 & 61780104 & 485.53 \\
14 & 610113872 & 610117230 & 3358.04 \\
15 & 6438810173 & 6438834700 & 24527.1 \\
\hline
\end{tabular}

Base, Modified densities (of distributions) and their differences for different values of ' $\mathrm{n}$ ' and ' $\alpha$ '.

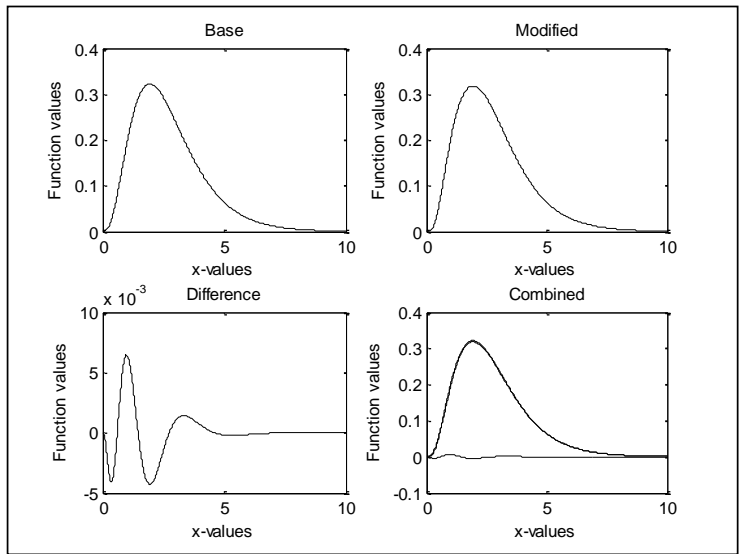

Fig. 6 (a). For the case of $\mathrm{n}=2$ and $\alpha=0.0016$. 


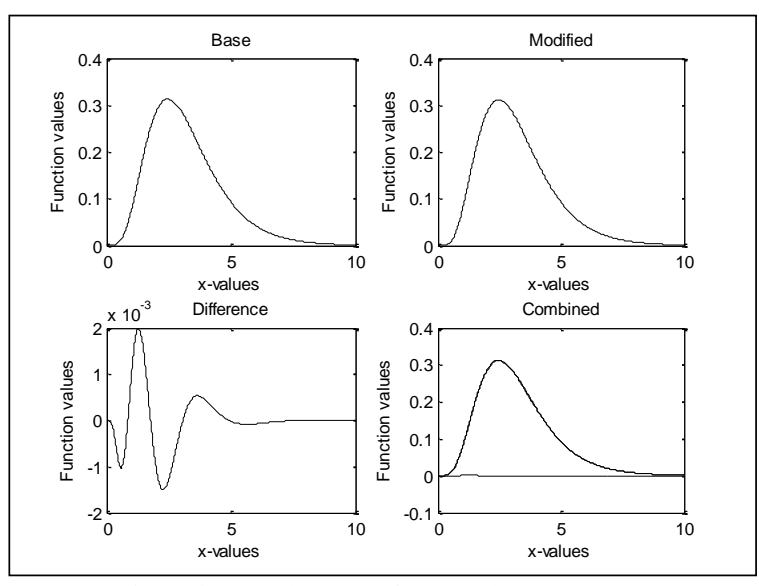

Fig. 6 (b). For the case of $n=3$ and $\alpha=0.0005$.

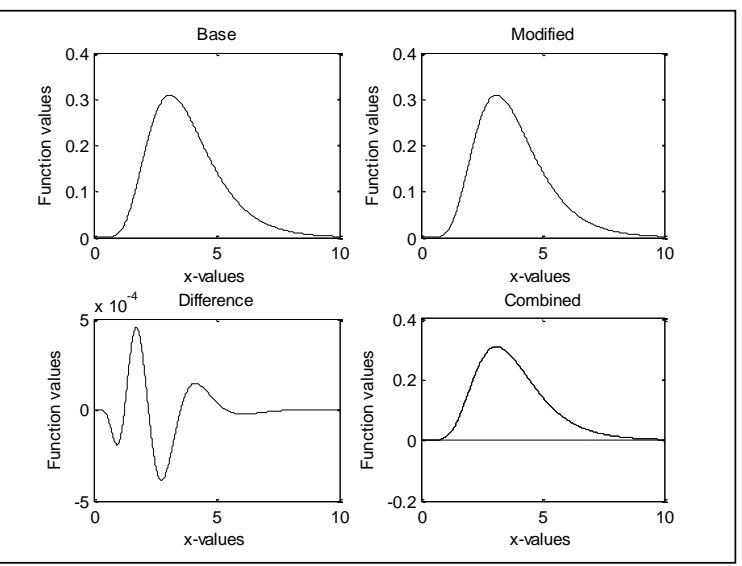

Fig. 6 (c). For the case of $\mathrm{n}=5$ and $\alpha=0.0001$.

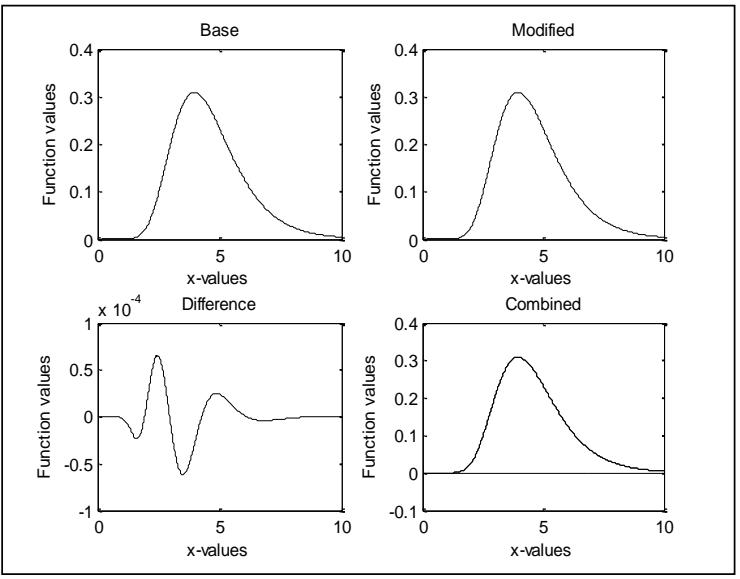

Fig. 6 (d). For the case of $\mathrm{n}=10$ and $\alpha=0.00002$.

\section{E. Weibull Distribution}

Here we consider Weibull Distribution, defined by:

$$
\begin{aligned}
& f(x)=\alpha \cdot \beta \cdot x^{\alpha-1} \cdot e^{-\beta \cdot x^{\alpha}}, 0 \leq x \leq \infty, \alpha>0, \beta>0 \\
& F(x)=1-e^{-3 x^{2}}, 0 \leq x \leq \infty, \text { where } \alpha=2 \text { and } \beta=3
\end{aligned}
$$

Minimum Order statistic distribution function of Weibull Distribution is:

$$
f_{n}(x)=n \cdot 6 \cdot x \cdot e^{-3 x^{2}} \cdot\left(e^{-3 x^{2}}\right)^{n-1}
$$

Maximum Order statistic distribution function of Weibull
Distribution is:

$$
f_{n}(x)=n \cdot 6 \cdot x \cdot e^{-3 x^{2}} \cdot\left(1-e^{-3 x^{2}}\right)^{n-1}
$$

where ' $\mathrm{n}$ ' is the sample size.

Now we consider the polynomials of order 5 as the modifier i.e. $\mathrm{k}=4, \mathrm{~m}=5$ (polynomial order), one gets $\mathrm{M}$, such that:

$$
\alpha \cdot \text { M. } \bar{b}=\bar{\Delta}
$$

Solving the above equation for ' $\bar{b}$ ', we get the modifier polynomial coefficients as ' $\bar{b}$, from which we get the following $5^{\text {th }}$ degree polynomial in ' $x$ ' with ' $n$ ', sample size.

\section{1) Minimum Order Statistics for Weibull Distribution}

\begin{tabular}{|c|c|c|}
\hline $\mathrm{n}$ & $g\left(x_{\mathrm{n}}\right)$ & $\theta=\max _{\mathrm{x}}\left|g\left(x_{\mathrm{n}}\right)\right|$ \\
\hline \multirow[t]{2}{*}{2} & $\begin{array}{c}(-0.030903+0.635727 * x- \\
3.845494 * x^{2}+9.440648 * x^{3}-\end{array}$ & \multirow{2}{*}{44.51171} \\
\hline & $\left.9.911061 * x^{4}+419 / 114 * x^{5}\right)^{*} e^{-x}$ & \\
\hline \multirow[t]{2}{*}{3} & $\begin{array}{c}(-0.011459+0.284615 * x- \\
2.082356 * x^{2}+6.191001 * x^{3}-\end{array}$ & \multirow{2}{*}{47.39561} \\
\hline & $\left.7.878382 * x^{4}+4547 / 1283 * x^{5}\right)^{*} e^{-x}$ & \\
\hline \multirow{2}{*}{5} & $\begin{array}{c}(-0.003265+0.103195 * x- \\
0.962506 * x^{2}+3.652645^{*} x^{3}-\end{array}$ & \multirow{2}{*}{50.51015} \\
\hline & $\left.5.938677 * x^{4}+3706 / 1085^{*} x^{5}\right)^{*} e^{-x}$ & \\
\hline \multirow{2}{*}{10} & $\begin{array}{c}(-0.0005899+0.025979 * x- \\
0.338337 * x^{2}+1.795094 * x^{3}-\end{array}$ & \multirow{2}{*}{53.88802} \\
\hline & $\left.4.084315^{*} x^{4}+2826 / 859^{*} x^{5}\right)^{*} e^{-x}$ & \\
\hline
\end{tabular}

The following Table XIX gives the polynomials and the corresponding ' $\theta$ ' values for chosen values of the ' $n$ '.

TABLE XIX: POLYNOMIALS AND THE CORRESPONDING ' $\theta$ ' VALUES FOR THE CHOSEN VALUES OF ' $\mathrm{N}$ '

Table XX below gives the ' $\alpha$ ' for the different ' $n$ ' and ' $\theta$ ' values.

TABLE XX: ‘ $\alpha$ ' FOR THE DIFFERENT 'N' AND ' $\theta$ ' VALUES

\begin{tabular}{ccccc}
\hline $\mathrm{n}$ & 2 & 3 & 5 & 10 \\
\hline$\theta$ & 44.51171 & 47.39561 & 50.51015 & 53.88802 \\
$\alpha=\frac{1}{\theta}$ & 0.022466 & 0.021099 & 0.019798 & 0.018557 \\
\hline
\end{tabular}

Thus, the general formula for modified minimum order statistic distribution is:

$f_{m}(x)=\left(n . f(x)(1-F(x))^{n-1}\right) \cdot\left\{1+\alpha g\left(x_{\mathrm{n}}\right)\right\}$

Thus, for instance, when $\mathrm{n}=2$, we have:

$$
f_{\mathrm{m}}(x)=12 \cdot x \cdot\left(e^{-3 x^{2}}\right)^{2} \cdot\left\{1+\alpha g\left(x_{\mathrm{n}}\right)\right\}, \text { and } \alpha \leq 0.023
$$

When $\mathrm{n}=3$, we have:

$$
\mathrm{f}_{\mathrm{m}}(\mathrm{x})=18 \cdot x \cdot\left(e^{-3 x^{2}}\right)^{3} \cdot\left\{1+\alpha g\left(x_{\mathrm{n}}\right)\right\} \text {, and } \alpha \leq 0.021
$$


When $\mathrm{n}=5$, we have:

$$
\mathrm{f}_{\mathrm{m}}(\mathrm{x})=30 \cdot x \cdot\left(e^{-3 x^{2}}\right)^{5} \cdot\left\{1+\alpha g\left(x_{\mathrm{n}}\right)\right\}, \text { and } \alpha \leq 0.020
$$

And, when $\mathrm{n}=10$, we have:

$$
\mathrm{f}_{\mathrm{m}}(\mathrm{x})=602 \cdot x \cdot\left(e^{-3 x^{2}}\right)^{10} \cdot\left\{1+\alpha g\left(x_{\mathrm{n}}\right)\right\} \text {, and } \alpha \leq 0.019
$$

Similarly, $f_{\mathrm{m}}(x)$ can be computed for any value of ' $\mathrm{n}$ '.

Table XXI (a), Table XXI (b), Table XXI (c) and Table XXI (d) clearly show that the first four moments are same for base and modified distributions and higher order moments are different.

Standardized moments for base, modified distributions, and their difference.

TABLE XXI (A): FOR THE CASE OF N=2 AND $\alpha=0.023$

\begin{tabular}{cccc}
\hline Moment & Base & Modified & Difference \\
\hline 1 & 0.36180063 & 0.36180063 & 0 \\
2 & 0.035766973 & 0.035766973 & 0 \\
3 & 0.63111061 & 0.63111061 & 0 \\
4 & 3.2450892 & 3.2450892 & 0 \\
5 & 5.9979693 & 5.9986067 & 0.0006374 \\
6 & 21.7910581 & 21.795496 & 0.0044379 \\
7 & 64.8165705 & 64.846631 & 0.0300605 \\
8 & 238.8265889 & 239.00658 & 0.1799911 \\
9 & 888.0432285 & 889.10556 & 1.0623315 \\
10 & 3603.816332 & 3610.0202 & 6.203868 \\
11 & 15301.3977 & 15337.859 & 36.4613 \\
12 & 68606.16758 & 68822.881 & 216.713422 \\
13 & 321656.8577 & 322964.68 & 1307.82235 \\
14 & 1574474.161 & 1582506.7 & 8032.539 \\
15 & 8015399.769 & 8065639 & 50239.231 \\
\hline
\end{tabular}

TABLE XXI (B): FOR THE CASE OF N=3 AND $\alpha=0.021$

\begin{tabular}{cccc}
\hline Moment & Base & Modified & Difference \\
\hline 1 & 0.295408978 & 0.29540898 & 0 \\
2 & 0.023844649 & 0.023844649 & 0 \\
3 & 0.63111066 & 0.63111066 & 0 \\
4 & 3.2450893 & 3.2450893 & 0 \\
5 & 5.9979693 & 5.9982109 & 0.0002416 \\
6 & 21.791058 & 21.792782 & 0.001724 \\
7 & 64.816570 & 64.828373 & 0.011803 \\
8 & 238.8265889 & 238.89811 & 0.0715211 \\
9 & 888.0432285 & 888.46934 & 0.4261115 \\
10 & 3603.816332 & 3606.3275 & 2.511168 \\
11 & 15301.3977 & 15316.28 & 14.8823 \\
12 & 68606.16758 & 68695.309 & 89.14142 \\
13 & 321656.8576 & 322198.95 & 542.0924 \\
14 & 1574474.161 & 1577827.2 & 3353.039 \\
15 & 8015399.769 & 8036521 & 21121.231 \\
\hline
\end{tabular}

TABLE XXI (C): FOR THE CASE OF N=5 AND $\alpha=0.020$

\begin{tabular}{cccc}
\hline Moment & Base & Modified & Difference \\
\hline 1 & 0.22882281 & 0.22882281 & 0 \\
2 & 0.014306789 & 0.014306789 & 0 \\
3 & 0.63111062 & 0.63111062 & 0 \\
4 & 3.2450893 & 3.2450893 & 0 \\
5 & 5.9979693 & 5.99804 & 0.0000707 \\
6 & 21.791058 & 21.791574 & 0.000516 \\
7 & 64.816570 & 64.820136 & 0.003566 \\
8 & 238.8265889 & 238.84844 & 0.0218511 \\
9 & 888.0432285 & 888.17468 & 0.1314515 \\
10 & 3603.816332 & 3604.5978 & 0.781468 \\
11 & 15301.3977 & 15306.069 & 4.6713 \\
12 & 68606.16758 & 68634.375 & 28.20742 \\
13 & 321656.8576 & 321829.5 & 172.6424 \\
14 & 1574474.161 & 1575550.8 & 1076.639 \\
15 & 8015399.769 & 8022225.5 & 6825.731 \\
\hline
\end{tabular}

TABLE XXI (D): FoR THE CASE OF N=10 AND $\alpha=0.019$

\begin{tabular}{cccc}
\hline Moment & Base & Modified & Difference \\
\hline 1 & 0.16180216 & 0.16180216 & 0 \\
2 & 0.007153395 & 0.007153395 & 0 \\
3 & 0.63111063 & 0.63111063 & 0 \\
4 & 3.2450892 & 3.2450892 & 0 \\
5 & 5.9979693 & 5.9979822 & 0.0000129 \\
6 & 21.791058 & 21.791155 & 0.000097 \\
7 & 64.816570 & 64.817251 & 0.000681 \\
8 & 238.8265889 & 238.83082 & 0.0042311 \\
9 & 888.0432285 & 888.0689 & 0.0256715 \\
10 & 3603.816332 & 3603.9704 & 0.154068 \\
11 & 15301.3977 & 15302.326 & 0.9283 \\
12 & 68606.16758 & 68611.82 & 5.65242 \\
13 & 321656.8576 & 321691.7 & 34.8424 \\
14 & 1574474.161 & 1574693 & 218.839 \\
15 & 8015399.769 & 8016799 & 1399.231 \\
\hline
\end{tabular}

Base, Modified densities (of distributions) and their differences for different values of ' $\mathrm{n}$ ' and ' $\alpha$ '.

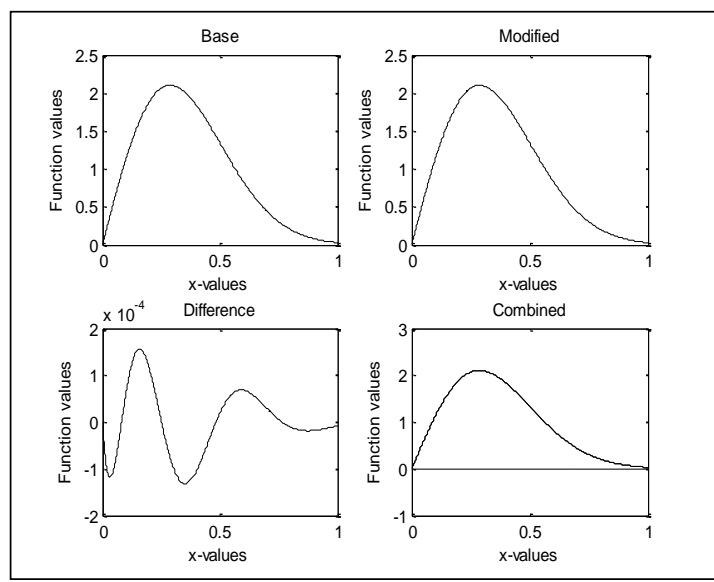

Fig. 7 (a). For the case of $\mathrm{n}=2$ and $\alpha=0.023$

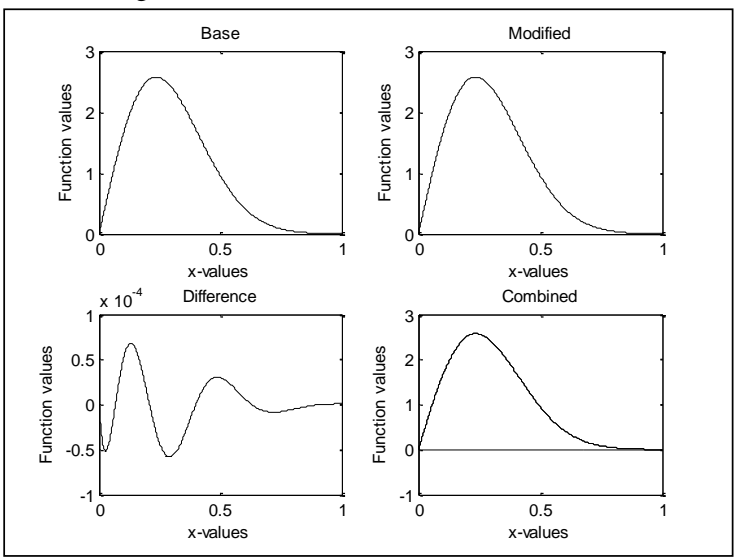

Fig. 7 (b). For the case of $\mathrm{n}=3$ and $\alpha=0.021$.

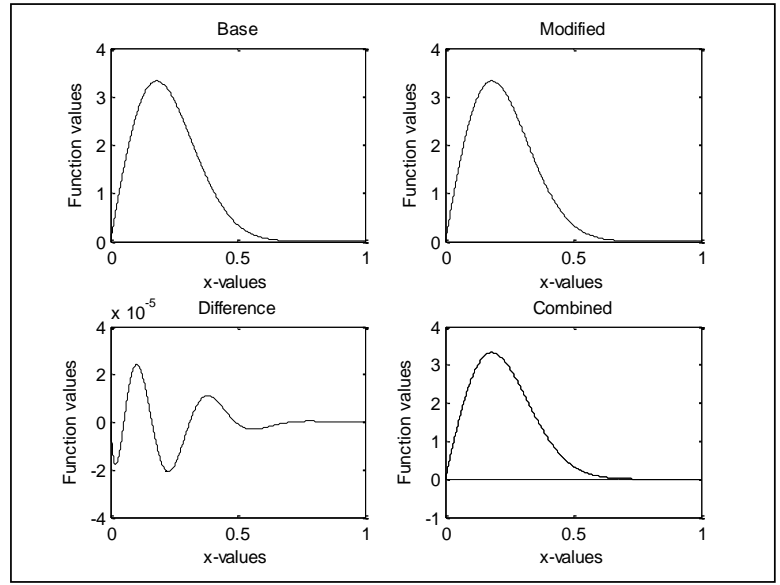

Fig. 7 (c). For the case of $n=5$ and $\alpha=0.020$. 


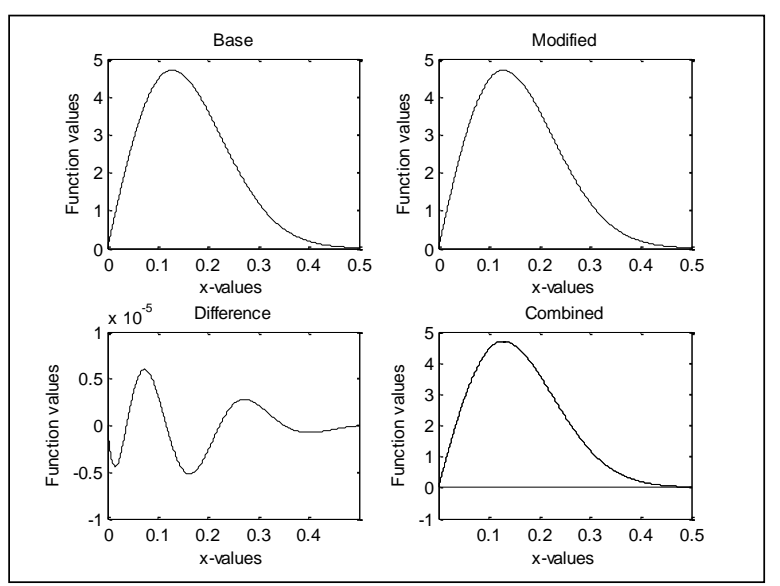

Fig. 7 (d). For the case of $n=10$ and $\alpha=0.019$.

\section{2) Maximum Order Statistics for Weibull Distribution}

The following Table XXII gives the polynomials and the corresponding ' $\theta$ ' values for the chosen values of ' $n$ '.

TABLE XXII: POLYNOMIALS AND THE CORRESPONDING ' $\theta$ ' VALUES FOR THE CHOSEN VALUES OF ' $\mathrm{N}$ '

\begin{tabular}{|c|c|c|}
\hline $\mathrm{n}$ & $g\left(x_{\mathrm{n}}\right)$ & $\theta=\max _{\mathrm{x}}\left|g\left(x_{\mathrm{n}}\right)\right|$ \\
\hline 2 & $\begin{array}{c}(-0.260100+2.5159902 * x- \\
8.308858 * x^{2}+12.076373 * x^{3}- \\
\left.7.888098 * x^{4}+2458 / 1307 * x^{5}\right) * e^{-x}\end{array}$ & 16.6901548 \\
\hline 3 & $\begin{array}{c}(-0.5430919+4.279469 * x- \\
12.116393 * x^{2}+15.629332 * x^{3}- \\
\left.9.285701 * x^{4}+1548 / 755^{*} x^{5}\right)^{*} e^{-x}\end{array}$ & 17.0425917 \\
\hline 5 & $\begin{array}{c}(-1.241299+7.955042 * x- \\
19.044230 * x^{2}+21.397410 * x^{3}- \\
\left.11.332383 * x^{4}+2365 / 1041 * x^{5}\right) * e^{-x}\end{array}$ & 17.2598622 \\
\hline 10 & $\begin{array}{c}(-3.133745+16.329680 * x- \\
32.667656 * x^{2}+31.392745 * x^{3}- \\
\left.14.505414 * x^{4}+5729 / 2220 * x^{5}\right) * e^{-x}\end{array}$ & 17.3183898 \\
\hline
\end{tabular}

Table XXIII below gives the ' $\alpha$ ' for the different ' $n$ ' and ' $\theta$ ' values.

\begin{tabular}{ccccc}
\multicolumn{4}{c}{ TABLE XXIII: ‘ $\alpha$ ' FOR THE DIFFERENT 'N' AND ‘ $\theta$ ' VALUES } \\
\hline $\mathrm{n}$ & 2 & 3 & 5 & 10 \\
\hline$\theta$ & $\begin{array}{c}16.690154 \\
8\end{array}$ & 17.0425917 & 17.2598622 & 17.3183898 \\
$\alpha=\frac{1}{\theta}$ & 0.059916 & 0.058677 & 0.057938 & 0.057742
\end{tabular}

Thus, the general formula for modified distributions is:

$$
f_{m}(x)=\left(n \cdot f(x) F(x)^{n-1}\right) \cdot\left\{1+\alpha g\left(x_{\mathrm{n}}\right)\right\}
$$

Thus, for instance, when $n=2$, we have:

$$
f_{\mathrm{m}}(x)=f_{m}(x)=\left(n \cdot f(x) F(x)^{n-1}\right) \cdot\left\{1+\alpha g\left(x_{\mathrm{n}}\right)\right\},
$$

and $\alpha \leq 0.060$.

When $\mathrm{n}=3$, we have:

$$
f_{\mathrm{m}}(x)=18 \cdot x \cdot\left(1-e^{-3 x^{2}}\right)^{2} \cdot e^{-3 x^{2}} \cdot\left\{1+\alpha g\left(x_{\mathrm{n}}\right)\right\}
$$

and $\alpha \leq 0.059$.

When $\mathrm{n}=5$, we have:

$$
f_{\mathrm{m}}(x)=30 \cdot x \cdot\left(1-e^{-3 x^{2}}\right)^{4} \cdot e^{-3 x^{2}} \cdot\left\{1+\alpha g\left(x_{\mathrm{n}}\right)\right\},
$$

and $\alpha \leq 0.058$

And, when $\mathrm{n}=10$, we have:

$f_{\mathrm{m}}(x)=60 . x \cdot\left(1-e^{-3 x^{2}}\right)^{9} \cdot e^{-3 x^{2}} \cdot\left\{1+\alpha g\left(x_{\mathrm{n}}\right)\right\}$, and $\alpha \leq 0.058$

Similarly, $f_{\mathrm{m}}(x)$ can be computed for any value of ' $\mathrm{n}$ '.

Table XXIV (a), Table XXIV (b), Table XXIV (c) and Table XXIV (d) clearly show that the first four moments are same for base and modified distributions and higher order moments are different.

Standardized moments for base, modified distributions and their difference.

\begin{tabular}{cccc}
\multicolumn{4}{c}{ TABLE XXIV (A): FOR THE CASE OF N=2 AND $\alpha=0.060$} \\
\hline Moment & Base & Modified & Difference \\
\hline 1 & 0.6615261 & 0.6615261 & 0 \\
2 & 0.0623832 & 0.0623832 & 0 \\
3 & 0.50824 & 0.50824 & 0 \\
4 & 3.2471 & 3.2471 & 0 \\
5 & 5.117408 & 5.121158 & 0.003750 \\
6 & 21.093347 & 21.113969 & 0.020622 \\
7 & 57.996152 & 58.13818 & 0.142028 \\
8 & 225.90747 & 226.7019 & 0.79443 \\
9 & 822.43254 & 827.069 & 4.63646 \\
10 & 3424.688 & 3451.1025 & 26.4145 \\
11 & 14614.08 & 14768.2 & 154.12 \\
12 & 66773.27 & 67682 & 908.73 \\
13 & 317926.7 & 323410 & 5483.3 \\
14 & 1587282.4 & 1621000 & 33717.6 \\
15 & 8246586.9 & 8460000 & 213413.1 \\
\hline
\end{tabular}

TABLE XXIV (B): FOR THE CASE OF N=3 AND $\alpha=0.059$

\begin{tabular}{cccc}
\hline Moment & Base & Modified & Difference \\
\hline 1 & 0.74499716 & 0.74499716 & 0 \\
2 & 0.05609035 & 0.05609035 & 0 \\
3 & 0.49149336 & 0.49149336 & 0 \\
4 & 3.3053239 & 3.3053239 & 0 \\
5 & 5.095844 & 5.09962 & 0.003776 \\
6 & 21.942139 & 21.962075 & 0.019936 \\
7 & 60.007795 & 60.151 & 0.143205 \\
8 & 241.61746 & 242.41923 & 0.80177 \\
9 & 888.24021 & 893.05 & 4.80979 \\
10 & 3800.2212 & 3828.079 & 27.8578 \\
11 & 16528.233 & 16696.08 & 167.847 \\
12 & 77478.224 & 78480 & 1001.776 \\
13 & 377804.73 & 383937 & 6132.27 \\
14 & 1936593.2 & 1975800 & 39206.8 \\
15 & 10331890.7 & 10588000 & 256109.3 \\
\hline
\end{tabular}

TABLE XXIV (C): FOR THE CASE OF N=5 AND $\alpha=0.058$

\begin{tabular}{cccc}
\hline Moment & Base & Modified & Difference \\
\hline 1 & 0.84406467 & 0.84406467 & 0 \\
2 & 0.04866594 & 0.04866594 & 0 \\
3 & 0.504028 & 0.504028 & 0 \\
4 & 3.3926232 & 3.3926232 & 0 \\
5 & 5.38216629 & 5.385652 & 0.00348571 \\
6 & 23.57669943 & 23.59536 & 0.01866057 \\
7 & 66.42705876 & 66.5689 & 0.14184124 \\
8 & 274.9432889 & 275.751 & 0.8077111 \\
9 & 1043.443504 & 1048.603 & 5.159496 \\
10 & 4614.875276 & 4644 & 29.124724 \\
11 & 20781.00683 & 20966.8 & 185.79317 \\
12 & 101035.2443 & 102362.32 & 1327.0757 \\
13 & 511516.7873 & 520710 & 9193.2127 \\
14 & 2726030.672 & 2775600 & 49569.328 \\
15 & 15134717.87 & 15595236 & 460518.13 \\
\hline
\end{tabular}


TABLE XXIV (D): FOR THE CASE OF N=10 AND $\alpha=0.058$

\begin{tabular}{cccc}
\hline Moment & Base & Modified & Difference \\
\hline 1 & 0.96747966 & 0.96747966 & 0 \\
2 & 0.040305855 & 0.040305855 & 0 \\
3 & 0.54918816 & 0.54918816 & 0 \\
4 & 3.5180255 & 3.5180255 & 0 \\
5 & 6.064009739 & 6.0668884 & 0.002878661 \\
6 & 26.30380519 & 26.3178 & 0.01399481 \\
7 & 79.40665313 & 79.53 & 0.12334687 \\
8 & 336.1194064 & 336.9 & 0.7805936 \\
9 & 1351.259729 & 1357 & 5.740271 \\
10 & 6224.354778 & 6262.7599 & 38.405122 \\
11 & 29575.4057 & 29809.424 & 234.0183 \\
12 & 151094.7793 & 155648.99 & 4554.2107 \\
13 & 807579.7406 & 838170.41 & 30590.6694 \\
14 & 4543038.1 & 4449212.3 & -93825.8 \\
15 & 26678741.63 & 30000000 & 3321258.37 \\
\hline
\end{tabular}

Base, Modified densities (of distributions) and their differences for different values of ' $n$ ' and ' $\alpha$ '.

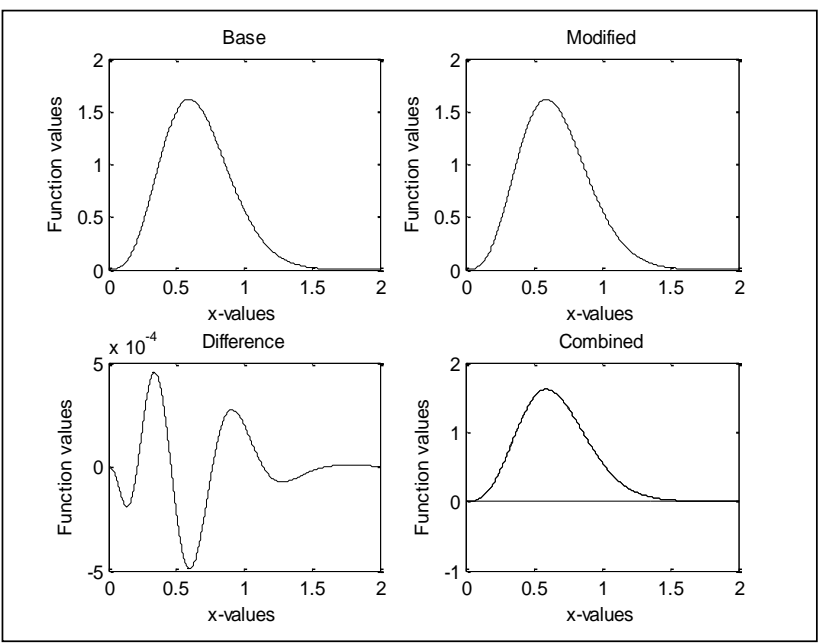

Fig. 8 (a). For the case of $\mathrm{n}=2$ and $\alpha=0.060$.

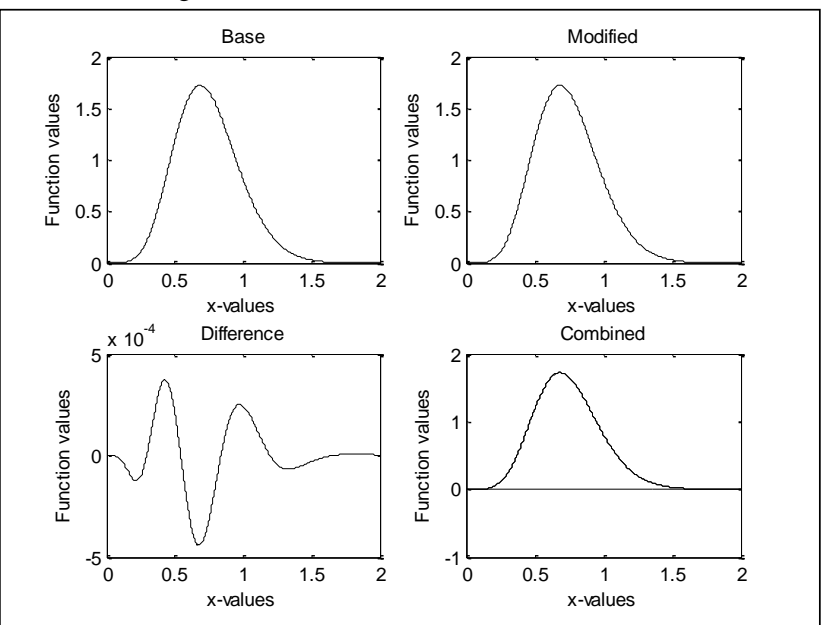

Fig. 8 (b). For the case of $n=3$ and $\alpha=0.059$

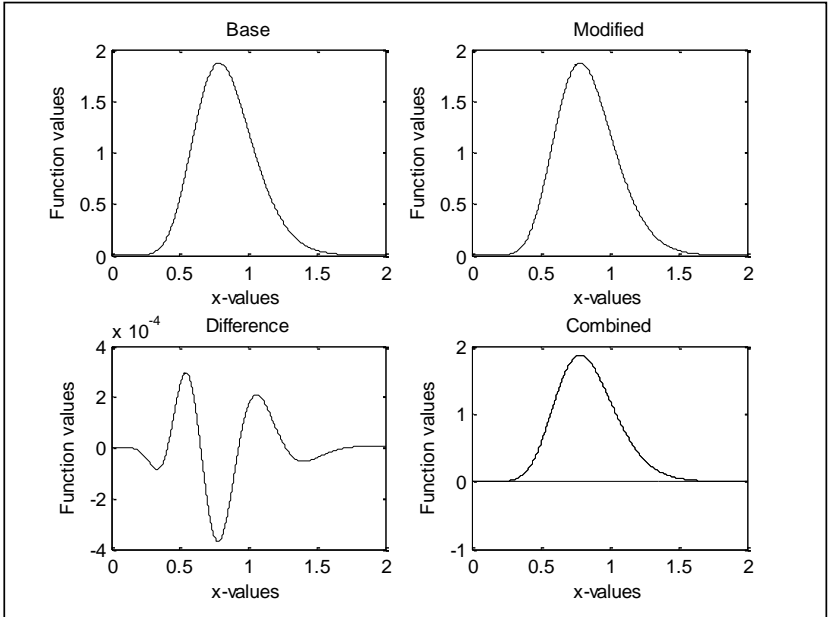

Fig. 8 (c). For the case of $n=5$ and $\alpha=0.058$.

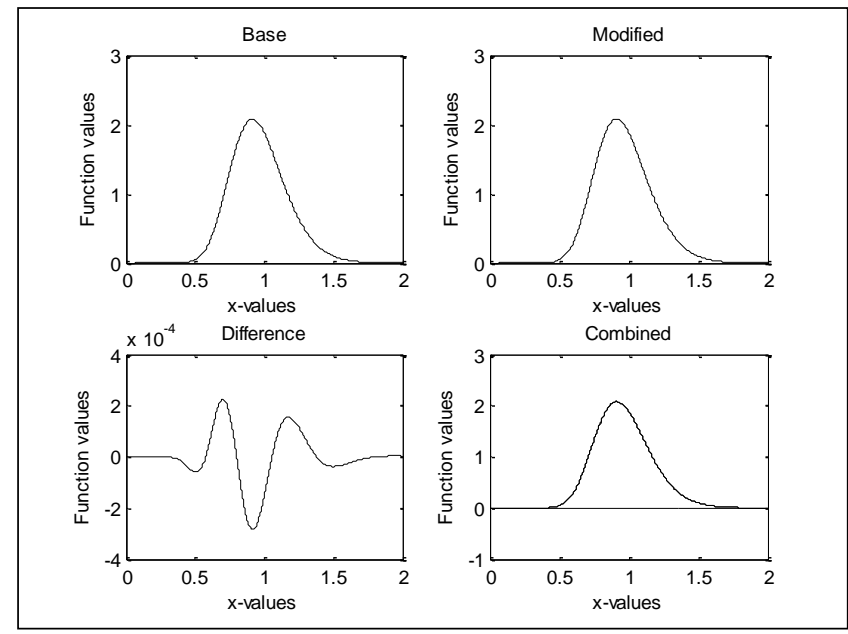

Fig. 8 (d). For the case of $n=10$ and $\alpha=0.058$.

\section{CONCLUSION}

It is evident from the above tables and figures that as ' $n$ ' increase for Rectangular/ Exponential distributions the higher order moment's differences are becoming bigger for both minimum and maximum order statistic distributions.

As expected, the higher order moments for the distributions with different ' $n$ ' are significantly different from one another and the shape of the corresponding density functions shows considerable wide pattern.

For instance, in the case of Rectangular and Exponential distributions the shape of the curves is similar for $n=5$ and 10 (Fig. $1 \mathrm{c}$ and Fig. $1 \mathrm{~d}$ ), but the higher order moments differences are quite significantly different large in maximum and minimum order statistic. Whereas for Gamma and Weibull distributions the shape of the curve is almost similar as ' $n$ ' increases and the moment differences are low.

The present problem opens up the possibility of the alternative approach to curve fitting [9], [10] using the statistical concepts of moments and choice of base distributions based upon the first few moments while modifiers are suitably chosen to get a good approximation to data. Unlike the least squares or the spline type of approximation the approach is to choose the higher moments to tally with the observed moments instead of the base distribution moments. The important question of choosing the parameters directly linked with the errors in fitting, like 
minimizing the maximum of absolute difference between the fitted function and data is yet to be explored. Since the base distributions themselves can be of varied shapes this approach should prove more satisfactory than the usual methods of curve fitting by choosing an overall function model.

One such situation, particularly of bivariate functions requiring such functions is in the area of image processing where the image can be thought of as a bivariate function with many peaks and troughs; it is difficult to envisage any simple function to approximate the image [2], [3] and piecewise local density estimation methods often are used. Instead, the present approach promises to give a more satisfactory approximation to reproduce the image (gray level frequency function) [11], [12], which is smooth and in explicit functional form.

\section{REFERENCES}

[1] Cramer, "Mathematical methods of Statistics", Princeton University, and Princeton University Press, 1946.

[2] Hu, M.K.," Visual Pattern Recognition by moment invariants" IRE Trans. Info. Theory, 1962, Volume IT-8, pp. 178-187.

[3] Dutt, V.A.K. "Multivariate and related statistical methods in pattern recognition". Un-Published Ph.D. Thesis-Osmania University, Hyderabad, 1995.

[4] Hara Gopal, V. V., Sampath Kumar, K. and Pandit, S.N.N, "On distributions, which differ only in higher order moments". The Aligarh Journal of Statistics, Vol. 24, pp. 121-141, 2004.

[5] Hara Gopal, V. V., Sampath Kumar, K. and Pandit, S.N.N, "A class of Bivariate Distributions, which differ only in higher moments" Contributions to Applied and Mathematical Statistics (CAMS Guwahati) Journal Vol. 2. pp. 32-42, March 2004(a).

[6] Hara Gopal, V. V., Sampath Kumar, K. and Pandit, S.N.N, "A class of Distributions differing in Higher order moments" - Proceedings of A.P. Akademi of Sciences Journal Vol. 8, No. 2. pp. 133-138, March 2004(b).

[7] Hara Gopal, V. V., Sampath Kumar, K. and Pandit, S.N.N" Qualitatively different distributions with same first few moments: A case study with 't' distribution", IJOMAS Journal Vol. 20, No. 2, pp157-166, .(March 2004(c)).

[8] Prokop, R. J., and Reeves, A.P. “A survey of moment-based techniques for un-occluded object representation and recognition", CVGPR: Graphical Models and Image Processing 54(5), 438-460, 1992.

[9] Ramberg, J.S., Dudewicz, E.J., Tadikamalla, P.R., Mykytka, E.F:” A Probability distribution and its uses in fitting Data", Techno metrics, Vol.21, and No.2, 1979.

[10] Sampath Kumar, K.: "On Distributions Which differs only in higher order moments", M.Phil. Thesis, Osmania University, Hyderabad, 2001.

[11] Teague, M.R, "Image Analysis via the General Theory of Moments" $J$. Optical Soc. Of Am., vol. 70, pp. 920-930, Aug. 1980.

[12] The, C. H and Chin, R. T: "On Image Analysis by the Method of Moments”, IEEE Trans, Pattern analysis and Machine Intelligence, vol. 10, pp. 496-513, 1998.

[13] Tukey, J. W. "The Practical Relationship between the common transformations of percentages of Counts and of amounts", Technical Report 36, Statistical Techniques Research Group, Princeton University, 1960. 